UCRL-TR-237333

\title{
Criticality Calculations Using \\ LANL and LLNL Neutron Transport Codes
}

\author{
by \\ Dermott E. Cullen, LLNL \\ Peter Brown, LLNL \\ Edward Lent, LLNL \\ Robert MacFarlane, LANL \\ Scott McKinley, LLNL \\ Contact \\ Dermott E. Cullen \\ Lawrence Livermore National Laboratory \\ P.O.Box 808/L-159 \\ Livermore, CA 94550 \\ Tele: 925-423-7359 \\ E.Mail: cullen1@llnl.gov \\ Website: http://home.comcast.net/ redcullen1
}

November 22, 2007

Approved for public release; further dissemination unlimited. 


\section{DISCLAIMER}

This document was prepared as an account of work sponsored by an agency of the United States government. Neither the United States government nor Lawrence Livermore National Security, LLC, nor any of their employees makes any warranty, expressed or implied, or assumes any legal liability or responsibility for the accuracy, completeness, or usefulness of any information, apparatus, product, or process disclosed, or represents that its use would not infringe privately owned rights. Reference herein to any specific commercial product, process, or service by trade name, trademark, manufacturer, or otherwise does not necessarily constitute or imply its endorsement, recommendation, or favoring by the United States government or Lawrence Livermore National Security, LLC. The views and opinions of authors expressed herein do not necessarily state or reflect those of the United States government or Lawrence Livermore National Security, LLC, and shall not be used for advertising or product endorsement purposes.

This work performed under the auspices of the U.S. Department of Energy by Lawrence Livermore National Laboratory under Contract DE-AC52-07NA27344. 
UCRL-TR-237333

\title{
Criticality Calculations Using LANL and LLNL Neutron Transport Codes
}

\author{
by \\ Dermott E. Cullen, LLNL \\ Peter Brown, LLNL \\ Edward Lent, LLNL \\ Robert MacFarlane, LANL \\ Scott McKinley, LLNL \\ Contact \\ Dermott E. Cullen \\ Lawrence Livermore National Laboratory \\ P.O.Box 808/L-159 \\ Livermore, CA 94550 \\ Tele: 925-423-7359 \\ E.Mail: cullen1@llnl.gov \\ Website: http://home.comcast.net/ redcullen1
}

November 22, 2007 


\section{Introduction}

In an earlier report [1] we considered three fast critical assemblies, each assembly is dominated by a different nuclear fuel: Godiva (U235), Jezebel (Pu239) and Jezebel23 (U233) [2]. We first showed the improvement in results when using the new ENDF/BVII.0 data [3], rather than the older, now frozen, ENDF/B-VI.8 data [4]. Next, we showed that our results could be obtained using any of a variety of Monte Carlo codes, i.e., the results were not specific to any single transport code.

Here our emphasis is only on our codes, rather than the nuclear data they use. For this paper all of our codes used the ENDF/B-VII.0 data [3], that we had already tested [1]. In this paper we concentrate on the same three critical assemblies, but here the emphasis is on demonstrating that we obtain the same results using any of the LANL and LLNL Monte Carlo and Sn codes. Here we show recent improvements in our Monte Carlo codes, and major improvements in our Sn results; at the time of our earlier paper [1], we had not yet achieved agreement between our Monte Carlo and Sn results. Only our Monte Carlo results were published in our earlier report, allowing us time to investigate the source of the differences between our Monte Carlo and Sn results. All of these differences have now been eliminated.

The bottom line is that in this report we show that using any of the LANL and LLNL Monte Carlo or Sn codes we obtain consistent integral and differential results. Furthermore it is worth noting that when any of these codes use the new ENDF/B-VII.0 data library, for the first time we are able to reproduce the expected K-eff values for all three assemblies to within the quoted accuracy of the models, namely $1.0+/-0.001$. This is a BIG improvement compared to the results obtained using the older ENDF/B-VI.8 data library.

\section{Why these Three Fast Three Systems?}

As a first step in this data testing here we limited our comparisons to only three fast critical assemblies [2]. These assemblies have been selected as the simplest measured systems; in each case both the composition and the geometry is as simple as possible. We have selected three homogeneous, spherical systems, each contains primarily one of the three fuels: Godiva (U235), Jezebel (Pu239) and Jezebel23 (U233).

Regardless of what type of critical assembly you are interested in, it is important to understand that all fission systems are driven by a source of fast $(\mathrm{MeV})$ fission neutrons emitted when an atom fissions. Since the results of any calculation can be no more accurate than the definition of the neutron source, we have decided to first insure that we can accurately model the source of fission neutrons in these three systems.

The intent is that after we have verified our results for these three fast systems we will consider progressively slower systems, working our way downward in medium neutron energy from fast to intermediate and ultimately to thermal systems. 


\section{What are we testing?}

In an earlier report we tested the ENDF/B-VII.0 data library, so we need not test it again. Here we are obviously testing all of the participating neutron transport codes, and less obvious, we are also testing the nuclear data processing codes used to prepare data for our transport codes. The most important point to understand is that neither our nuclear data, nor our codes are perfect. This and preceding comparisons have led to important improvements in both our data and our codes.

One important step that is often "overlooked" is the nuclear data processing step that comes between the basic evaluated data and our neutron transport codes. We should not forget that even though all of the transport codes included in this study say they used the ENDF/B-VII.0 data, there has actually been a lot of assumptions and manipulation of the data done by nuclear data processing codes before our transport codes ever see the data. Often it is the assumptions made by our data processing codes that define and sometimes limit the accuracy of the subsequent use of the data in our applications.

For use in this report, each of the four Monte Carlo codes, had its own nuclear data processing code,

COG - PREPRO2007 [18] and undocumented code ENDFtoCOG

MCNP - NJOY [8]

MERCURY - MCFGEN [16]

TART - PREPRO2007 [18] and undocumented code TARTMAKER

For the Sn codes in principle there are two different nuclear data processing codes,

AMTRAN - NDFGEN [15]

ARDRA - NDFGEN [15]

PARTISN - NOY/TRANSX [17]

However, for this report all of the Sn data used by the three Sn codes was produced using NJOY/TRANSX; NDFGEN is still a work in progress.

Important as the data processing step is, trying to explicitly include analysis of all of the nuclear data processing codes was deemed beyond the scope of this paper. However, by comparing the detailed output of our transport codes we can implicitly test our nuclear data processing codes, and at least in the case of NJOY [5] we do explicitly show the influence that this often "overlooked” step can have on our results.

Related to nuclear data processing codes is the approximations used by each code. It was deemed beyond the scope of this paper to go into the details of the approximations used by each nuclear data processing code and how it limits our transport codes. I will merely mention a few points: 1) All four Monte Carlo codes now use continuous energy cross sections (earlier versions of some of these codes only used multi-group data). but the accuracy to which the continuous energy cross sections are defined varies from one code to another, 2) Some of these codes use an unresolved resonance treatment, while others do not; for the three fast critical assemblies the unresolved resonance region is not as important as it is for slower systems, 3) Some of these codes use continuous secondary 
energy and angular distributions, whiles others use equally probable bins, 4) There are a variety of methods used to interpolate secondary energy/angle distributions. These are but a few of the differences used by each code systems. So it would be naïve to assume that saying they all use the ENDF/B-VII.0 data uniquely defines how they are actually interpreting the data. What is important to us in this study is whether or not all of these approximations result in any important differences in the answers. To summarize, for this study we are testing both nuclear data processing codes and transport codes, and the results we present must be considered as what is produced due to each overall system, including both nuclear data processing code and transport codes.

\section{K-eff is NOT Enough}

Another important point to understand is that calculating K-eff is necessary, but not sufficient, to guarantee that our data and codes are accurate. In our comparisons we try to go one step further to insure that not only are integral parameters, such as K-eff, accurate, but so are our differential results. Specifically, when we consider the definition,

K-eff $=\frac{\text { Production }}{\text { Absorption }+ \text { Leakage }}=\frac{\text { Production }}{\text { Re moval }}$

Here neutron production, absorption and leakage, are each one integral parameter, defined by integrating over the entire system in space, direction, and energy. For our comparisons we look at integral parameters, such as K-eff, but we also look in detail at the differential flux (fluence), production, absorption and leakage, versus neutron energy. These detailed comparisons often lead to identifying problems with our nuclear data processing codes and/or our transport codes, ultimately leading to improvements in both data and codes.

\section{A Pragmatic Standard: Which Code is Right?}

We do not assume that the answers from one code are any better or worse than the answers from any other code. Rather we attempt to establish what I call a pragmatic standard, based on comparing results from as many different codes as possible. As we will see "BEST" may be defined in several different ways, for example, we could define BEST as the most accurate interpretation of the ENDF/B data, or we could define BEST as the most accurate physical models, or in any number of other ways. Here we will present results from as many codes as possible, explain the sources of differences in results, and let users decide what is BEST for their use. 


\section{Definition of the Three Systems}

For these comparisons all codes MUST use only ENDF/B-VII.0 data [3]. If you wish to compare to results using other nuclear data, please feel free to do so using the results from this study; but in this case this would have to be a separate study organized by you.

All three models are taken from ref. [2]. Each is a solid sphere with only one uniform spatial zone. Therefore to uniquely define each model we need only specify: radius, density and composition. All systems are at room temperature (293.6 Kelvin). All of these models are designed to produce K-eff close to 1.0. The table below includes parameters exactly as they are quoted in ref. [2].

\begin{tabular}{|c|c|c|c|}
\hline Model & $\begin{array}{l}\text { HMF001-002 } \\
\text { Godiva }\end{array}$ & $\begin{array}{c}\text { PMF001-001 } \\
\text { Jezebel }\end{array}$ & $\begin{array}{l}\text { UMF001-001 } \\
\text { Jezebel23 }\end{array}$ \\
\hline Radius (cm) & 8.7407 & 6.3849 & 5.9838 \\
\hline Density (grams/cc) & 18.74 & 15.61 & 18.424 \\
\hline $\begin{array}{c}\text { Composition } \\
\text { (atoms/barns-cm) }\end{array}$ & $\begin{array}{ll}235 \mathrm{U} & 4.4994 \mathrm{e}-2 \\
238 \mathrm{U} & 2.4984 \mathrm{e}-3 \\
234 \mathrm{U} & 4.9184 \mathrm{e}-4\end{array}$ & $\begin{array}{lr}239 \mathrm{Pu} & 3.7047 \mathrm{e}-2 \\
240 \mathrm{Pu} & 1.7512 \mathrm{e}-3 \\
241 \mathrm{Pu} & 1.1674 \mathrm{e}-4 \\
69 \mathrm{Ga} & 8.26605 \mathrm{e}-4 \\
71 \mathrm{Ga} & 5.48595 \mathrm{e}-4\end{array}$ & $\begin{array}{l}4.6712 \mathrm{e}-2 \\
5.9026 \mathrm{e}-4 \\
2.8561 \mathrm{e}-4 \\
1.4281 \mathrm{e}-5\end{array}$ \\
\hline
\end{tabular}

Derived Quantities based on the above radius and density

\begin{tabular}{|c|c|c|c|}
\hline Volume (cc) & 2797.224 & 1090.312 & 897.4697 \\
\hline Mass (grams) & 52419.98 & 17019.77 & 16534.98 \\
\hline
\end{tabular}

For PMF001-001 (Jezebel) the original model specification was for natural gallium. For use with ENDF/.B-VII.0 data this has been replaced by the isotopes,

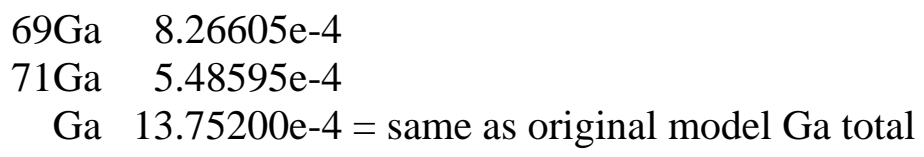

Ga 13.75200e-4 = same as original model Ga total

\section{Consistency and Accuracy}

It wasn't too long ago that when calculating criticality we were pleased if we could calculate K-eff within 0.5\%, e.g., any results between 0.995 and 1.005 was considered indistinguishable $=1.0$. Today we feel that we can calculate systems to much better precision, but not to infinite precision; we are pleased if we can calculate K-eff to within $0.1 \%$, e.g., any results between 0.999 and 1.001 is considered indistinguishable $=1.0$. In ref [2] these models are quoted to produce integral results (K-eff) as follows,

Godiva (U235) $=1.0+/-0.001$

Jezebel $(\mathrm{Pu} 239=1.0+/-0.002$

Jezebel23 $(\mathrm{U} 233)=1.0+/-0.002$ 
There are many factors that contribute to limiting the accuracy to which we can calculate results, among these factors are: uncertainty in the parameters for the systems we calculate: uncertainties in the nuclear data we use, uncertainties in the computer codes we use, and more. None of these factors are perfect and in the real world we must make allowances for these uncertainties by avoiding assuming we can calculate results to too high precision. As an example, let's take a look at an obvious uncertainty in our models.

Anyone who reads the documentation for these systems in ref [2] will find pictures of these systems, and can see that they are not "exactly" simple spherical systems completely isolated from the surrounding world. From this you can appreciate that our simplified isolated, homogeneous, spherical three systems are idealized models of the actual measured systems; this is a major contributing factor in the quoted uncertainty of these models.

Naturally nuclear data can be a major contributing factor to uncertainty, but we have already verified the accuracy of results using ENDF/B-VII.0 data, and here we are only interested in the variation of the results between codes.

\section{Statistical Accuracy}

We are naturally very interested to know the accuracy of our results. But we must use care to insure that we do not confuse the overall accuracy of our results with the statistical uncertainty reported by our Monte Carlo transport codes. For example, if we run our Monte Carlo codes long enough our results will indicate no significant statistical uncertainty in our answers. In this case it is incorrect to assume that this means our answers are "perfect". All this really means is that the statistical uncertainty is much less than the overall uncertainty due to other factors.

For the systems that we are calculating here the uncertainty due to the models are, as defined above, of the order of $1.0+/-0.001$ in K-eff. Therefore in order to be sure that we are not introducing any significant additional uncertainty, we should insure that the statistical uncertainty from our Monte Carlo calculations is much less than this.

The results presented in this paper are based on 1 billion $\left(10^{9}\right)$ histories for most codes, and 10 billion $\left(10^{10}\right)$ histories for TART [6]. At this level the statistical accuracy of the results are much smaller than the inherent inaccuracies of other factors. Therefore below we do not quote code errors +/- the statistical uncertainty for each result, because they are not a good indicator of the overall accuracy of our results.

As a guide toward judging the accuracy of the quoted results, the below table presents TART results and their statistical accuracy for each of the three systems, for both expected (recommended) and analog results, for several different number of histories run. These results are all based on running 100 settle batches, followed by 10,000 active batches (settle batches are only 1\% overhead). The total number of histories run is based on changing the number of source neutrons per batch: 10 billion $=1,000,000 ; 1$ billion = 100,000; 100 million $=10,000$ per batch . 
To help guide you, note that relative to the K-eff values which are all very close to 1.0, an uncertainty of $+/-1.0 \mathrm{E}-5$, means an uncertainty of $+/-0.00001$, or 1 in the last quoted digit of K-eff. So that anything less than this, as with the 10 billion expected results, means less than $+/-0.00001$ in the quoted K-eff. Conversely, with the 100 million analog results $+/-1.0 \mathrm{E}-4$, means $+/-0.00010$ or more.

From these results we can see that by 10 billion histories the statistical uncertainty is 1 or less in the last quoted digit. Since, based on the uncertainties in the models, this is two orders of magnitude below the +/- 0.001 accuracy we are trying to achieve. In other words the statistical uncertainties are irrelevant compared to other uncertainties.

K-eff expected and analog results vs. the number of histories run

\begin{tabular}{|c|l|l|l|}
\hline & 10 billion & 1 billion & 100 million \\
\hline Godiva Expected & $1.00019+/-7.162 \mathrm{E}-6$ & $1.00017+/-2.287 \mathrm{E}-5$ & $0.99997+/-7.311 \mathrm{E}-5$ \\
Analog & $1.00018+/-1.319 \mathrm{E}-5$ & $1.00021+/-4.218 \mathrm{E}-5$ & $0.99991+/-1.338 \mathrm{E}-4$ \\
\hline Jezebel Expected & $1.00010+/-7.215 \mathrm{E}-6$ & $1.00008+/-2.262 \mathrm{E}-5$ & $0.99996+/-7.174 \mathrm{E}-5$ \\
Analog & $1.00011+/-1.525 \mathrm{E}-5$ & $1.00011+/-4.793 \mathrm{E}-5$ & $1.00002+/-1.538 \mathrm{E}-4$ \\
\hline Jezebel23 Expected & $0.99983+/-6.919 \mathrm{E}-6$ & $0.99985+/-2.179 \mathrm{E}-5$ & $0.99988+/-7.008 \mathrm{E}-5$ \\
Analog & $0.99983+/-1.360 \mathrm{E}-5$ & $0.99986+/-4.302 \mathrm{E}-5$ & $0.99990+/-1.371 \mathrm{E}-4$ \\
\hline
\end{tabular}

\section{What is Important and What is NOT Important?}

We will be focusing on K-eff values calculated by a variety of codes. We define,

K-eff $=\frac{\text { Production }}{\text { Absorption }+ \text { Leakage }}=\frac{\text { Production }}{\text { Re moval }}$

Where Production, Absorption and Leakage are integrated over the entire system. Besides the scalar values of Production, Absorption and Leakage, we will also compare the energy dependent spectra for these quantities (see, Appendix B and C for their definitions). These energy dependent spectra are extremely helpful in explaining differences between integral results and also serve to insure that even when we obtain the same integral results, the details of the calculations are correct, i.e., as stated earlier, the correct value of K-eff is necessary, but not sufficient, to insure the accuracy of our results. These spectra are also extremely important because they allow us to determine what energy ranges are important for any systems.

We determine what energies ranges are important by normalizing the integral of all spectra to unity, and then integrating the energy dependent spectra, first starting from zero integral at low energy and working our way up toward unity integral at high energy, and then starting from zero integral at high energy and working our way down toward unity integral at low energy. 
These three fast critical systems are so similar that it is sufficient for us to illustrate results of these integrals for only one system; the following page shows plots of these integrals for Godiva.

From the below plots we can see the median energies for these systems, which is the point where the two integrals cross at $50 \%$. Here we can see that the median energy for flux, production, absorption and leakage are all very close to $1 \mathrm{MeV}$, as they are for all three of these systems. This is a clear indication of how truly "fast" these critical systems are. For comparison, when we look at well thermalized system we find median energies close to $(3 / 2) \mathrm{KT}$, at a fraction of $1 \mathrm{eV}$, more than a million times slower than the fast systems we are focusing on here.

From the figures below, what we can see from the integral from low energy to high is that the integrals up to about $10 \mathrm{keV}$ are only roughly $0.1 \%$ of the total integrals. Similarly, what we can see from the integral from high energy to low is that the integrals above about $10 \mathrm{MeV}$ are only roughly $0.1 \%$ of the total integrals. We can summarize these results as,

Below $10 \mathrm{keV} \sim 0.1 \%$

Above $10 \mathrm{MeV} \sim 0.1 \%$

$10 \mathrm{keV}$ to $10 \mathrm{MeV} \sim 99.8 \%$

What this means is that as far as K-eff is concerned, results will be very insensitive to how accurately we calculate results below $10 \mathrm{keV}$ and above $10 \mathrm{MeV}$, so that in our comparisons we will concentrate on the important energy range $10 \mathrm{keV}$ to $10 \mathrm{MeV}$. We will also discuss differences we see outside of this energy range, but only to explain the sources of these differences, not because they will have any major impact on K-eff.

But a word of caution here: K-eff is not the only parameter of interest. For example, if you are interested in reaction rates, such as $(n, 2 n)$, then the high energy range will be very important for your application. So please do not make the mistake of assuming that what we are saying is that the low and higher energies are generally not important; we are only saying that as far as these fast critical systems to define K-eff, the lower and higher energy ranges are not important. 

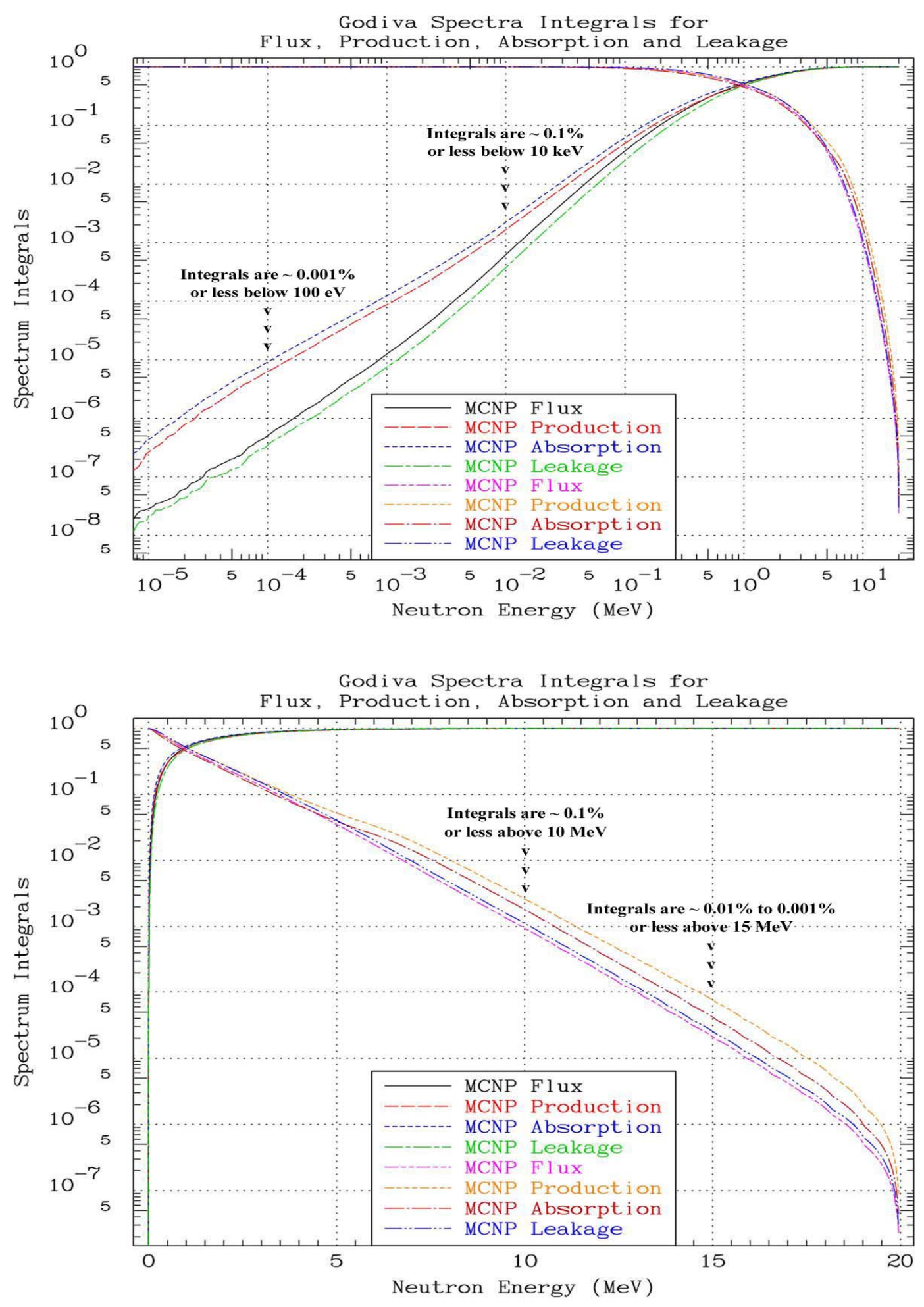


\section{MCNP Original versus SMOOTH Results}

In an earlier study [1] we pointed out a few deficiencies in ENDF/B-VII.0 data. These included approximations in neutron spectra,

1) The use of histogram data extending all the way down to $0 \mathrm{eV}$.

2) Too few tabulated points in fission spectra.

ENDF/B-VII.0 is frozen until 2009, so that we cannot immediately eliminate these problems from our basic data files. However, all of the codes included in this study have been updated to compensate for these limitations. Specifically,

1) At low energy the codes use a $\sqrt{E}$, rather than histogram shape; this only affects spectra below about $10 \mathrm{keV}$.

2) Additional tabulated energy points have been added to fission spectra; this only affects spectra above about $10 \mathrm{MeV}$.

The net effect with these improvements is a lower flux at low and high energy. Below we show the effect on Godiva (the other systems shows similar differences). MCNP Original is based on a literal interpretation of ENDF/B-VII.0 data, and MCNP Smooth is based on these improvements.

From the following figures, we can see that below $10 \mathrm{keV}$ a $\sqrt{E}$ shape will deviate rapidly from the constant, histogram approximation. We can also see that above $10 \mathrm{MeV}$ the improved shape of the fission spectra causes the flux to be lowered by $5 \%$ to $10 \%$.

We should mention that neither of these improvements has any significant effect on integral parameters. The integral of the flux below $10 \mathrm{keV}$ is only about $0.1 \%$ of the total, and similarly the integral above $10 \mathrm{MeV}$ is also only about $0.1 \%$ of the total, with about $99.8 \%$ of the integral of the flux being between $10 \mathrm{keV}$ and $10 \mathrm{MeV}$.

Since all of our codes have now been updated to include these improvements, all of the following results are based on including these results. In particular, the MCNP results are all based on MCNP Smooth results, rather than MCNP Original. This convention makes it easier for us to see the spread in the low and high energy results. 

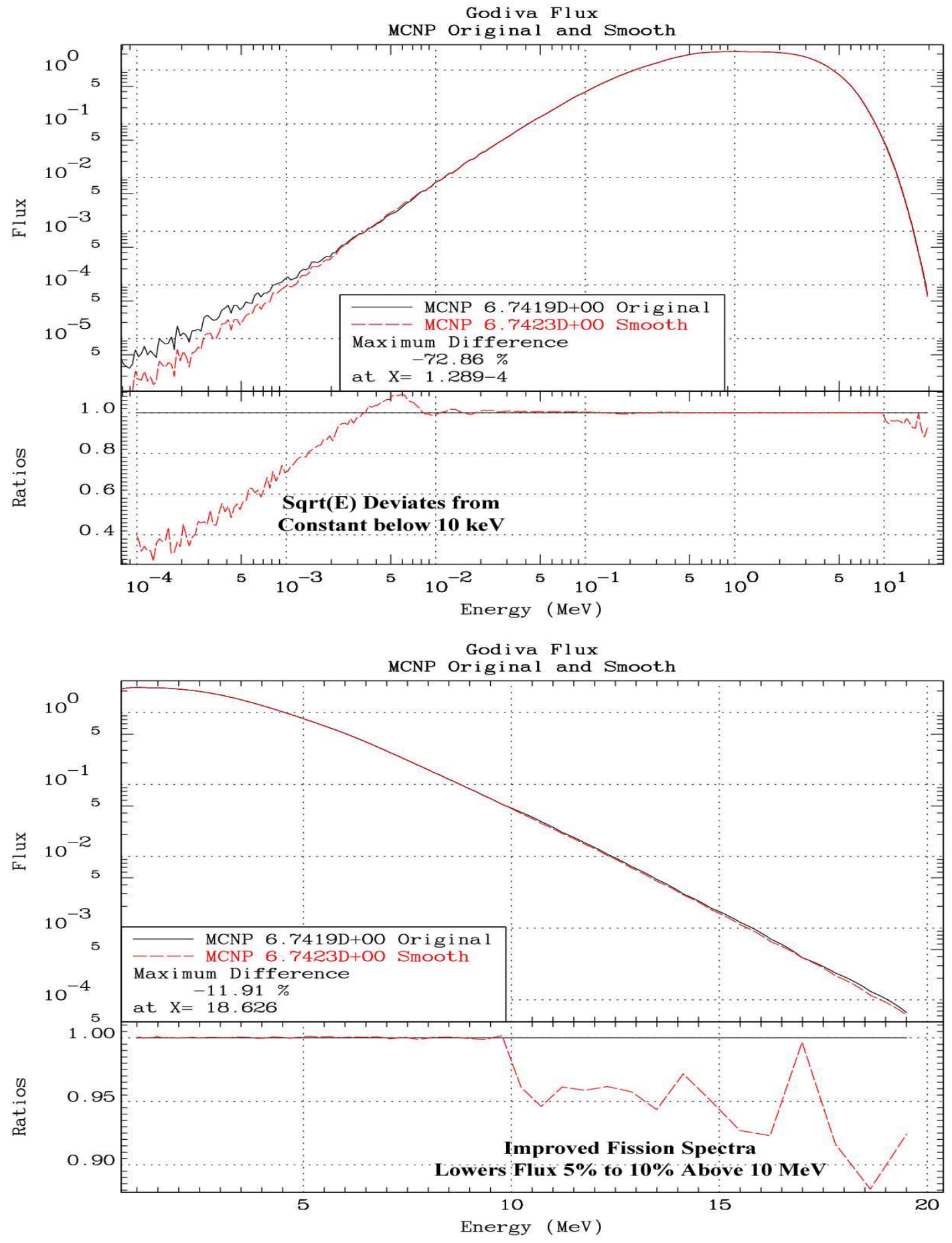


\section{Contributions to this comparison}

Only LANL and LLNL Monte Carlo and Sn codes were invited to participate in this code comparison. To date in alphabetical order contributions were received from four Monte Carlo codes and three Sn codes,

$\begin{array}{lll}\text { Code } & \text { Type } & \text { Contributors } \\ \text { AMTRAN } & \text { Sn } & \text { Peter Brown, LLNL [7] } \\ \text { ARDRA } & \text { Sn } & \text { Peter Brown, LLNL [8] } \\ \text { COG } & \text { MC } & \text { Edward Lent, LLNL [9] } \\ \text { MCNP } & \text { MC } & \text { Robert MacFarlane, LANL [10] } \\ \text { MERCURY } & \text { MC } & \text { Scott McKinley, LLNL [11] } \\ \text { PARTISN } & \text { Sn } & \text { Robert MacFarlane, LANL [12] } \\ \text { TART } & \text { MC } & \text { Dermott Cullen, LLNL [6] }\end{array}$

Summary of K-eff Results using ENDF/B-VII.0 data and Seven Transport Codes

\begin{tabular}{|c|c|c|c|}
\hline & Godiva & Jezebel & Jezebel23 \\
\hline COG & 1.00048 & 1.00009 & 0.99981 \\
MCNP & 0.99985 & 0.99986 & 0.99964 \\
MERCURY & 1.00027 & 1.00075 & 1.00075 \\
TART & 1.00010 & 1.00033 & 0.99980 \\
AMTRAN (Sn) & 1.00013 & 0.99986 & 0.99989 \\
ARDRA (Sn) & 1.00013 & 0.99987 & 0.99990 \\
PARTISN (Sn) & 1.00001 & 1.00004 & 0.99995 \\
\hline
\end{tabular}

The most important point to note from the above results is that ALL of the codes reported K-eff results are within what we consider to be the acceptable range 1.0 +/0.001. This illustrates that these codes are already able to use ENDF/B-VII.0 data, and that they produce reliable results, at least for K-eff. 


\section{Integral Results}

Godiva Seven Code Comparisons

\begin{tabular}{|c|c|c|c|c|c|c|c|}
\hline & $\begin{array}{c}\text { MCNP } \\
\text { MC }\end{array}$ & $\begin{array}{c}\text { COG } \\
\text { MC }\end{array}$ & $\begin{array}{c}\text { MERCURY } \\
\text { MC }\end{array}$ & $\begin{array}{c}\text { TART } \\
\text { MC }\end{array}$ & $\begin{array}{c}\text { ARDRA } \\
\text { Sn }\end{array}$ & $\begin{array}{c}\text { AMTRAN } \\
\text { Sn }\end{array}$ & $\begin{array}{c}\text { PARTISN } \\
\text { Sn }\end{array}$ \\
\hline Flux & 6.74192 & 6.73692 & 6.74113 & 6.74106 & 6.74144 & 6.74144 & 6.74274 \\
\hline Production & 1.00000 & 1.00000 & 1.00000 & 1.00000 & 1.00000 & 1.00000 & 1.00000 \\
\hline Absorption & 0.43009 & 0.43022 & 0.42988 & 0.43009 & 0.43007 & 0.43007 & 0.43012 \\
\hline Leakage & 0.57005 & 0.56931 & 0.56985 & 0.56981 & 0.56980 & 0.56980 & 0.56987 \\
\hline Removal & 1.00014 & 0.99952 & 0.99973 & 0.99990 & 0.99987 & 0.99987 & 0.99999 \\
\hline K-eff & 0.99985 & 1.00048 & 1.00027 & 1.00010 & 1.00013 & 1.00013 & 1.00001 \\
\hline $\begin{array}{c}\text { Removal } \\
\text { Time } \\
\text { nanoseconds }\end{array}$ & 6.21699 & 6.23075 & 6.19188 & 6.21739 & 6.21357 & 6.21357 & 6.21740 \\
\hline
\end{tabular}

Jezebel Seven Code Comparisons

\begin{tabular}{|c|c|c|c|c|c|c|c|}
\hline & $\begin{array}{c}\text { MCNP } \\
\text { MC }\end{array}$ & $\begin{array}{c}\text { COG } \\
\text { MC }\end{array}$ & $\begin{array}{c}\text { MERCURY } \\
\text { MC }\end{array}$ & $\begin{array}{c}\text { TART } \\
\text { MC }\end{array}$ & $\begin{array}{c}\text { ARDRA } \\
\text { Sn }\end{array}$ & $\begin{array}{c}\text { AMTRAN } \\
\text { Sn }\end{array}$ & $\begin{array}{c}\text { PARTISN } \\
\text { Sn }\end{array}$ \\
\hline Flux & 4.68642 & 4.68622 & 4.68428 & 4.68581 & 4.68752 & 4.68752 & 4.68683 \\
\hline Production & 1.00000 & 1.00000 & 1.00000 & 1.00000 & 1.00000 & 1.00000 & 1.00000 \\
\hline Absorption & 0.32795 & 0.32795 & 0.32780 & 0.32789 & 0.32804 & 0.32804 & 0.32796 \\
\hline Leakage & 0.67219 & 0.67195 & 0.67140 & 0.67178 & 0.67210 & 0.67209 & 0.67200 \\
\hline Removal & 1.00014 & 0.99990 & 0.99920 & 0.99967 & 1.00014 & 1.00013 & 0.99996 \\
\hline K-eff & 0.99986 & 1.00009 & 1.00080 & 1.00033 & 0.99986 & 0.99987 & 1.00004 \\
\hline $\begin{array}{c}\text { Removal } \\
\text { Time } \\
\text { nanoseconds }\end{array}$ & 3.72886 & 3.73359 & 3.72154 & 3.72884 & 3.72813 & 3.72813 & 3.72858 \\
\hline
\end{tabular}

Jezebel23 Seven Code Comparisons

\begin{tabular}{|c|c|c|c|c|c|c|c|}
\hline & $\begin{array}{c}\text { MCNP } \\
\text { MC }\end{array}$ & $\begin{array}{c}\text { COG } \\
\text { MC }\end{array}$ & $\begin{array}{c}\text { MERCURY } \\
\text { MC }\end{array}$ & $\begin{array}{c}\text { TART } \\
\text { MC }\end{array}$ & $\begin{array}{c}\text { ARDRA } \\
\text { Sn }\end{array}$ & $\begin{array}{c}\text { AMTRAN } \\
\text { Sn }\end{array}$ & $\begin{array}{c}\text { PARTISN } \\
\text { Sn }\end{array}$ \\
\hline Flux & 4.12318 & 4.12274 & 4.11710 & 4.12264 & 4.12284 & 4.12284 & 4.12269 \\
\hline Production & 1.00000 & 1.00000 & 1.00000 & 1.00000 & 1.00000 & 1.00000 & 1.00000 \\
\hline Absorption & 0.38792 & 0.38795 & 0.38789 & 0.38792 & 0.38795 & 0.38795 & 0.38793 \\
\hline Leakage & 0.61244 & 0.61224 & 0.61137 & 0.61228 & 0.61216 & 0.61215 & .61211 \\
\hline Removal & 1.00036 & 1.00019 & 0.99926 & 1.00020 & 1.00011 & 1.00010 & 1.00004 \\
\hline K-eff & 0.99964 & 0.99981 & 1.00075 & 0.99980 & 0.99989 & 0.99990 & 0.99995 \\
\hline $\begin{array}{c}\text { Removal } \\
\text { Time } \\
\text { nanoseconds }\end{array}$ & 3.20374 & 3.20539 & 3.19246 & 3.20305 & 3.20482 & 3.20481 & 3.20403 \\
\hline
\end{tabular}

A lot has changed since 1965 when Keepin published his estimates of removal times for these systems, but his 1965 values are reasonably close to what we calculate today; his values are: Godiva 6.04, Jezebel 3.00, Jezebel23 (Skidoo) 2.82 nanoseconds [13]. This is admittedly not great agreement, but not bad after 40 years. 


\section{Seven Code Energy Dependent Flux Comparisons}

Below we compare the scalar flux (actually fluence) from seven codes for these three fast critical systems. Here we defined the flux integrated over the entire system per neutron produced; this is simply the pathlength traveled by neutrons in $\mathrm{cm}$.

The figures below contain a lot of data and you may not be able to follow the energy dependent variation of the flux from any one code. That's o.k. These plots indicate that a given code has a problem only if it stands out from the crowd. So if the flux from a given code does not stand out, its results are sufficiently similar to the results from all other codes and we judge the results to be acceptable.

The below comments are roughly the same for all three systems. Below we show a comparison of the scalar flux over four energy ranges:

1) $100 \mathrm{eV}$ to $20 \mathrm{MeV}$, for an overall view of the results

2) $10 \mathrm{keV}$ to $10 \mathrm{MeV}$, which is roughly $99.8 \%$ of the integral of the flux;

3) low energy range, $100 \mathrm{eV}$ to $10 \mathrm{keV}, 0.1 \%$ of integral

4) high energy range, 1 to $20 \mathrm{MeV}, 0.1 \%$ of integral

The number after the code name is in all cases the integral of the flux from $10^{-5} \mathrm{eV}$ to 20 $\mathrm{MeV}$ per neutron produced in each system. The top 2/3 of each plot is of the data, and the bottom $1 / 3$ is the ratio of the all sets of data to MCNP.

For simple integral parameters, such as K-eff, they are only sensitive to the flux between $10 \mathrm{keV}$ and $10 \mathrm{MeV}$.

The low and high energy ranges, which have low probabilities, can effect other important parameters, such as $(n, 2 n)$ reaction rates, which are sensitive to the high energy range.

The below discussion of self-shielding helps to explain the differences we see at lower energies. As explained below, the results for MERCURY, AMTRAN and ARDRA do not account for some or all self-shielding effects.

The overall conclusion is that for all three systems all of the codes agree closely in the important, high probability energy range $10 \mathrm{keV}$ to $10 \mathrm{MeV}$. At low and high energy ranges the spread in results is larger; below $10 \mathrm{keV}$ down to $100 \mathrm{eV}$, up to +/ $50 \%$, and above $10 \mathrm{MeV}$, up to about $+/-10 \%$. The larger differences at low and high energy are due to statistical uncertainties in the Monte Carlo answers, in these low probability energy ranges, and because as yet there is not consensus on how to uniquely correct the ENDF/B-VII.0 data at low ( $\sqrt{E}$ variation) and high energy (more densely spaced energy points in tabulated fission spectra). 


\section{Differential Results: Godiva}
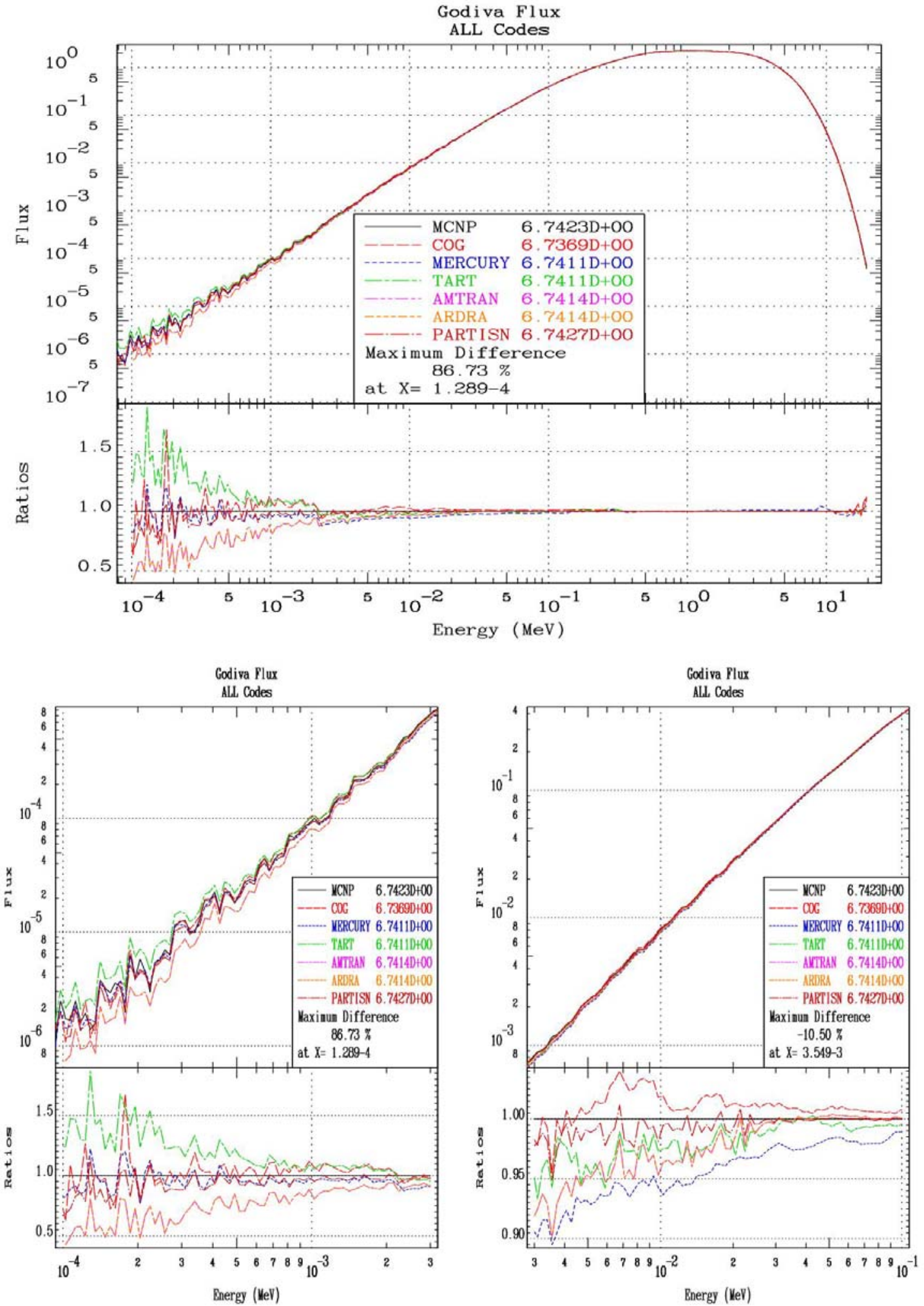


\section{Differential Results: Godiva}
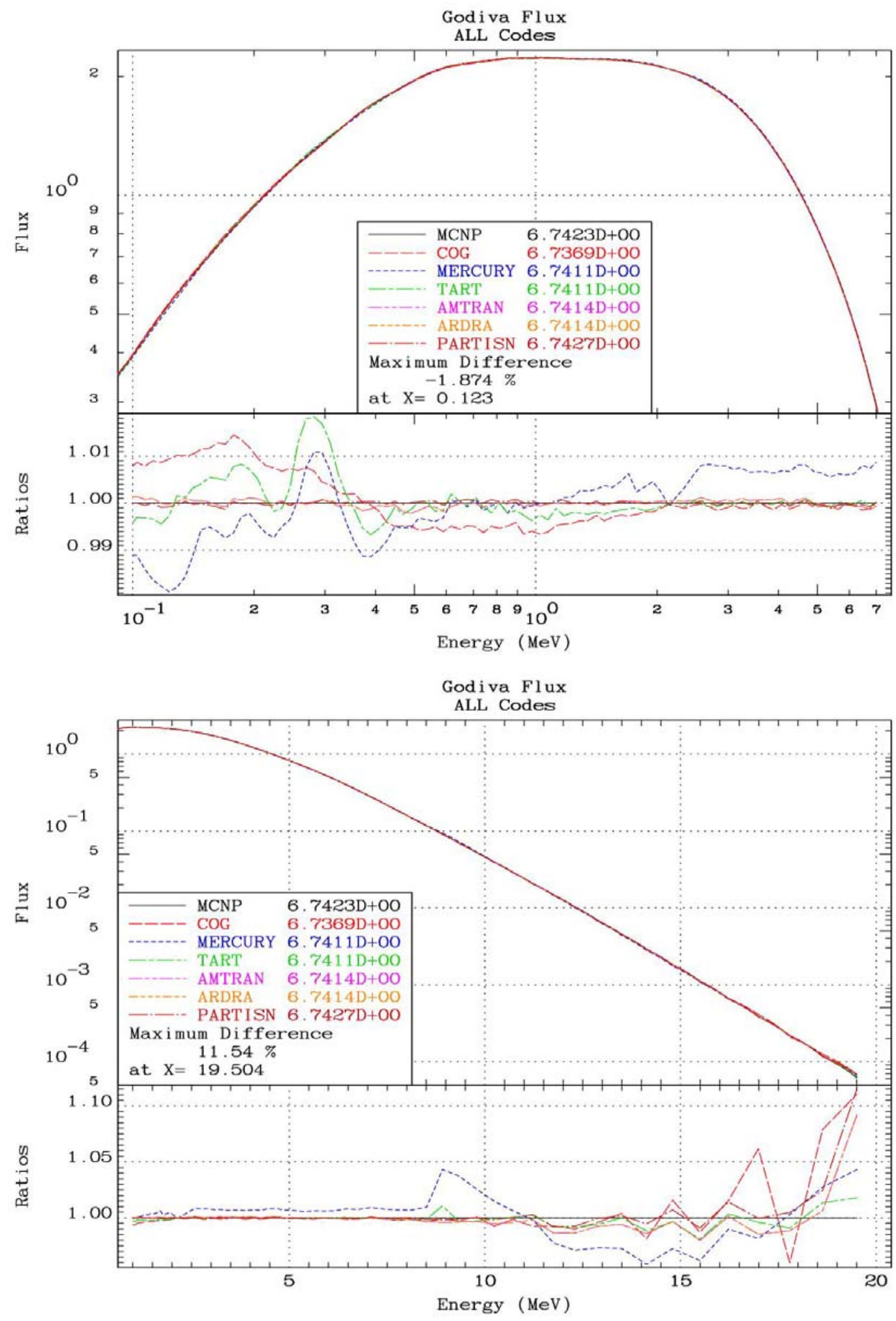


\section{Differential Results: Jezebel}
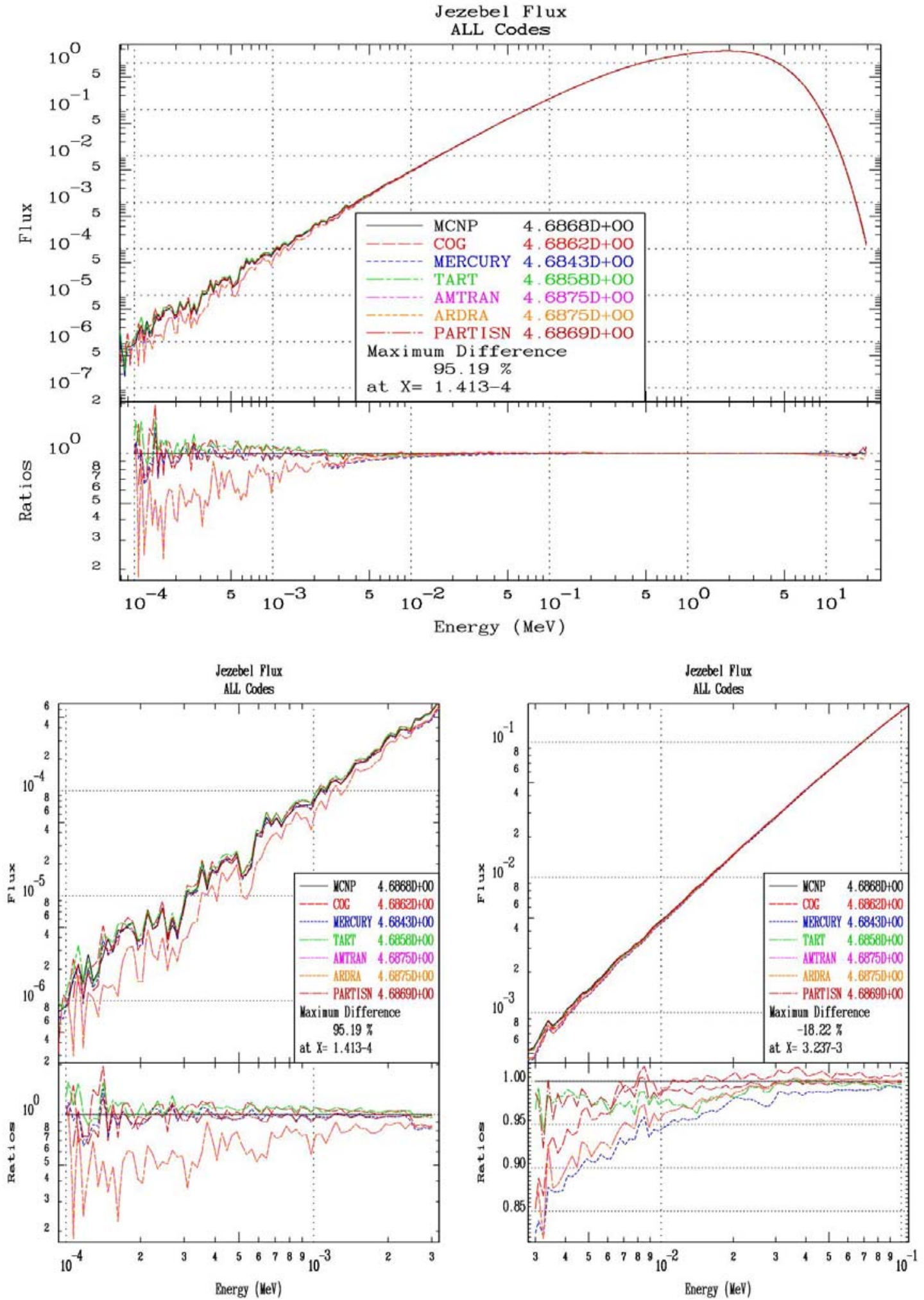


\section{Differential Results: Jezebel}
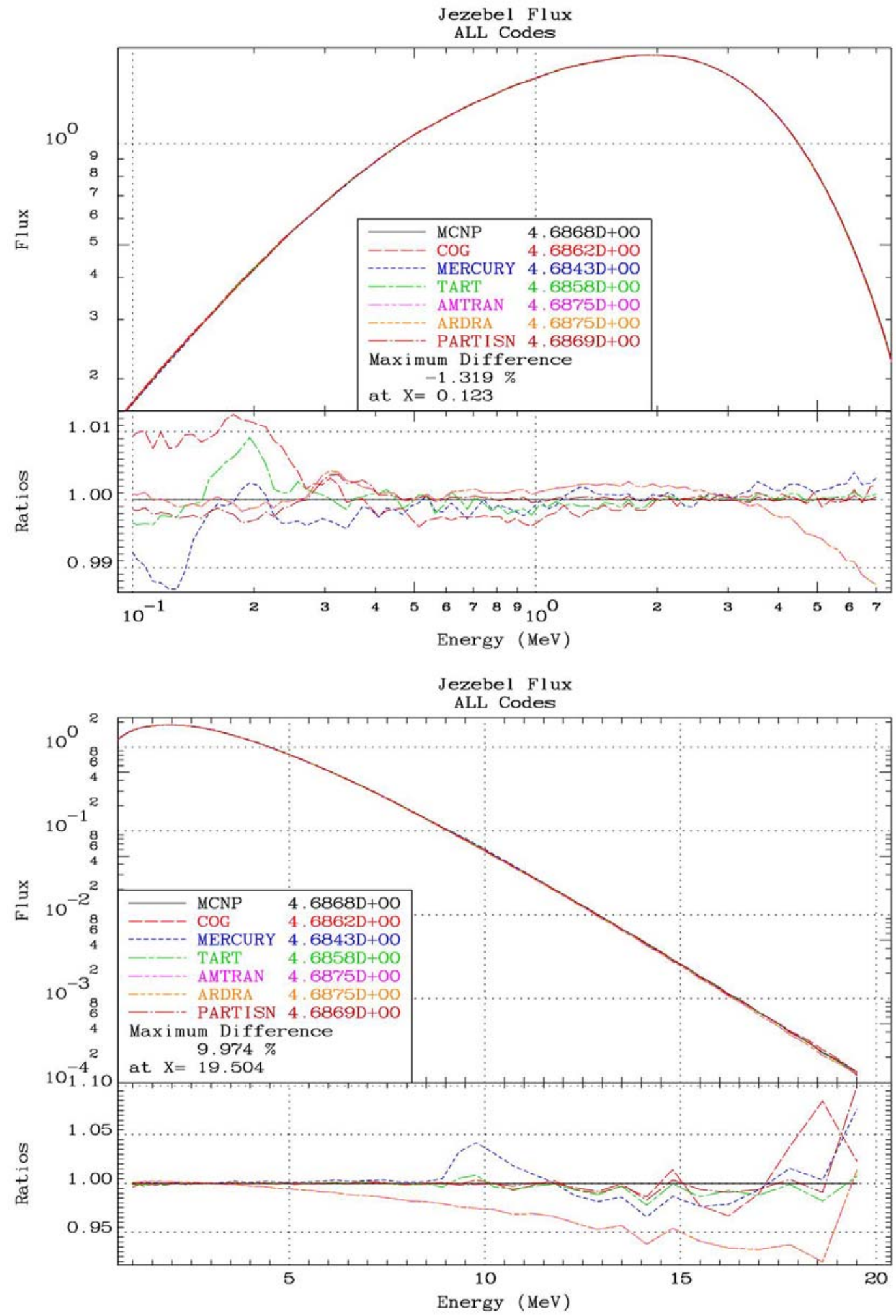


\section{Differential Results: Jezebel23}
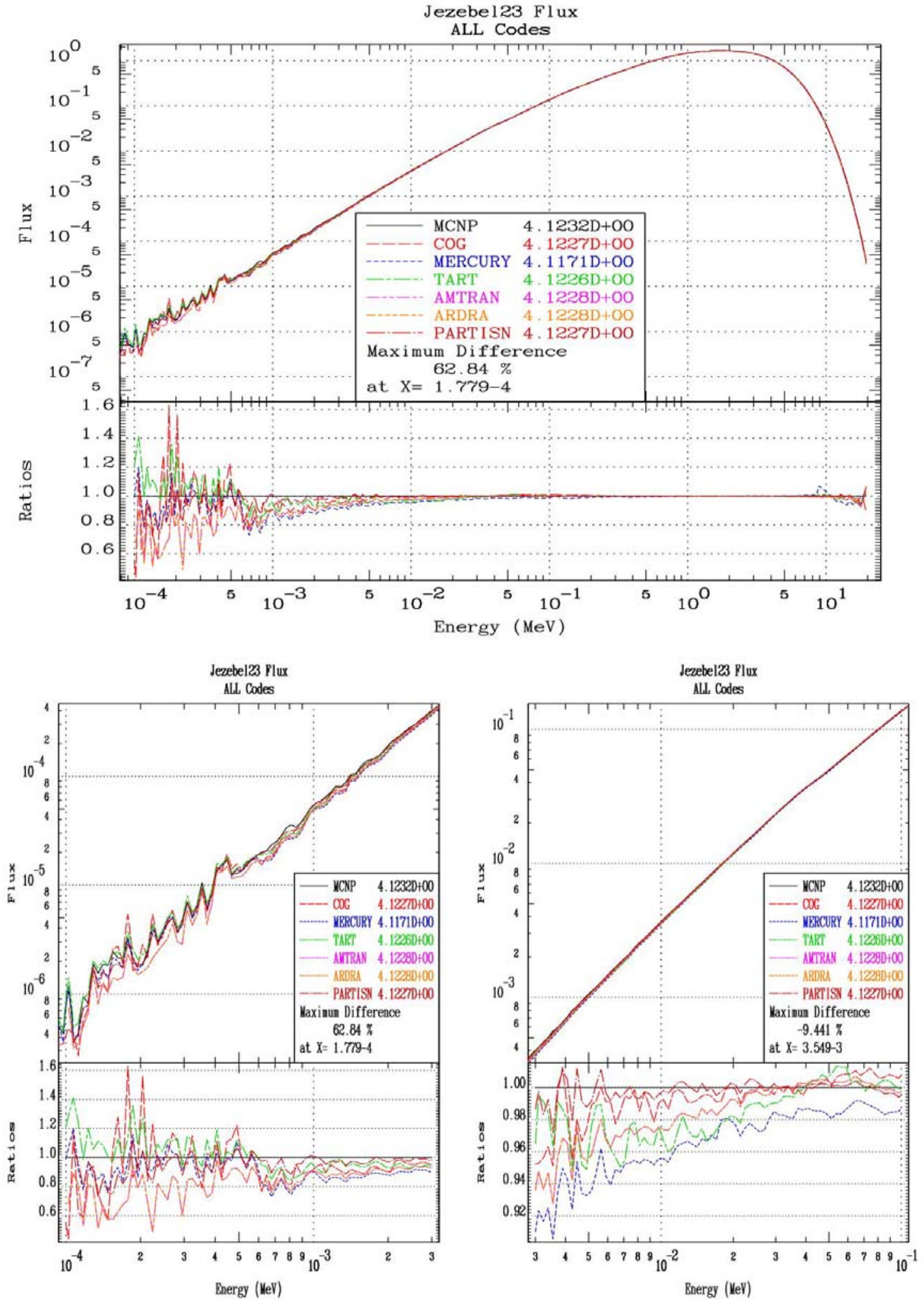


\section{Differential Results: Jezebel23}
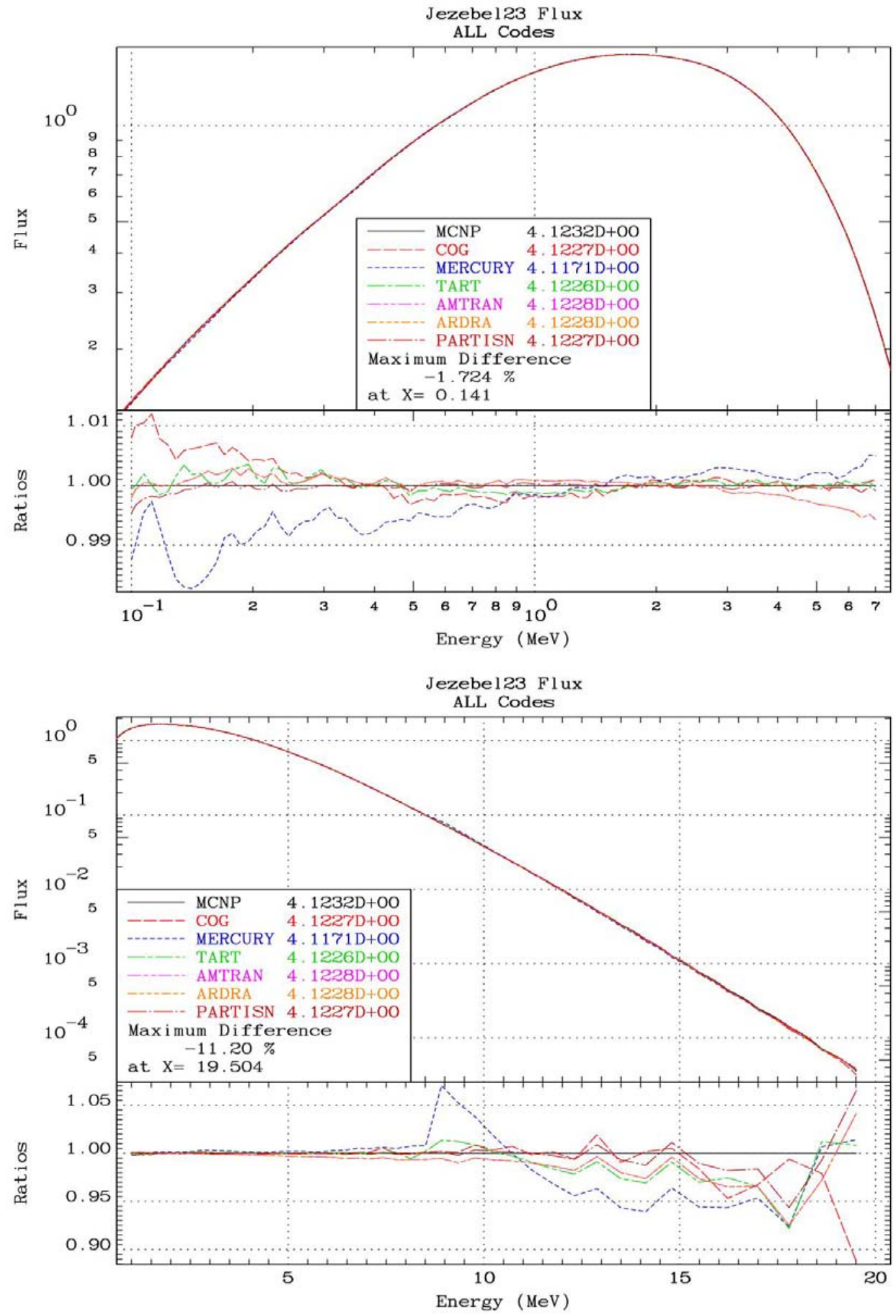


\section{Continuous Energy versus Multigroup: Self-Shielding}

The four Monte Carlo codes use continuous energy cross sections, and the three Sn codes use multigroup cross sections. For tallies the four Monte Carlo codes all use the TART 616 tally bins, which 50 bins per energy decade from $10^{-5} \mathrm{eV}$ up to $20 \mathrm{MeV}$. The three Sn codes use one group from $10^{-5} \mathrm{eV}$ up to $100 \mathrm{eV}$, and the TART 616 group structure above $100 \mathrm{eV}$ up to $20 \mathrm{MeV}$, for a total of 267 groups. For these three fast neutron systems there is essentially no flux below $100 \mathrm{eV}$, and since all seven codes are using the same tally bins (groups) above this point, we expect to obtain very similar results.

An obvious potential source of difference between the Monte Carlo and Sn code results may be due to the difference between using continuous energy cross sections (Monte Carlo codes) and multigroup cross sections (Sn codes). Since TART can run using either continuous energy cross sections or 616 group cross sections we can easily determine the effect of using one model or the other. A related source of difference is self-shielding in the unresolved resonance region. Of the seven codes represented here only MERCURY does not have an unresolved resonance self-shielding treatment.

The below table compares TART integral results for the three systems using continuous and unshielded multigroup cross sections. The differences in the results are highlighted in yellow. We can see that the differences are quite small, usually only in the fourth or fifth digit of the results, except for the removal time, which is more sensitive to the suppression of the low energy flux by the unshielded multigroup cross sections. But even here the differences are quite small.

\begin{tabular}{|c|c|c|c|c|c|c|}
\hline & $\begin{array}{c}\text { Godiva } \\
\text { Continuous }\end{array}$ & $\begin{array}{c}\text { Godiva } \\
\text { Multigroup }\end{array}$ & $\begin{array}{c}\text { Jezebel } \\
\text { Continuous }\end{array}$ & $\begin{array}{c}\text { Jezebel } \\
\text { Multigroup }\end{array}$ & $\begin{array}{c}\text { Jezebel23 } \\
\text { Continuous }\end{array}$ & $\begin{array}{c}\text { Jezebel23 } \\
\text { Multigroup }\end{array}$ \\
\hline Flux & 6.74106 & 6.74153 & 4.68581 & 4.68521 & 4.12264 & 4.12258 \\
\hline Production & 1.00000 & 1.00000 & 1.00000 & 1.00000 & 1.00000 & 1.00000 \\
\hline Absorption & 0.43009 & 0.43008 & 0.32789 & 0.32791 & 0.38792 & 0.38792 \\
\hline Leakage & 0.56981 & 0.56976 & 0.67178 & 0.67168 & 0.61228 & 0.61228 \\
\hline Removal & 0.99990 & 0.99984 & 0.99967 & 0.99958 & 1.00020 & 1.00020 \\
\hline K-eff & 1.00010 & 1.00016 & 1.00033 & 1.00042 & 0.99980 & 0.99980 \\
\hline $\begin{array}{c}\text { Removal } \\
\text { Time } \\
\text { nanoseconds }\end{array}$ & 6.21739 & 6.21558 & 3.72884 & 3.72641 & 3.20305 & 3.20267 \\
\hline
\end{tabular}

The figures below show that self-shielding affects the flux spectra only below roughly 20 $\mathrm{keV}$. Below this point the larger unshielded multigroup cross sections suppress the flux more at progressively lower energies. As stated above, for these three fast systems the integral of the flux up to $10 \mathrm{keV}$ is only about $0.1 \%$ of the total. Since self-shielding only affects the flux below roughly $20 \mathrm{keV}$, we can understand why we see little effect on the integral parameters.

Be aware that the results shown here are the worst case scenario, because in this comparison TART used unshielded multigroup cross sections. By using NJOY/TRANSX to produce the Sn data, the multigroup data used by these three Sn codes can be self-shielded to even further improve results. 

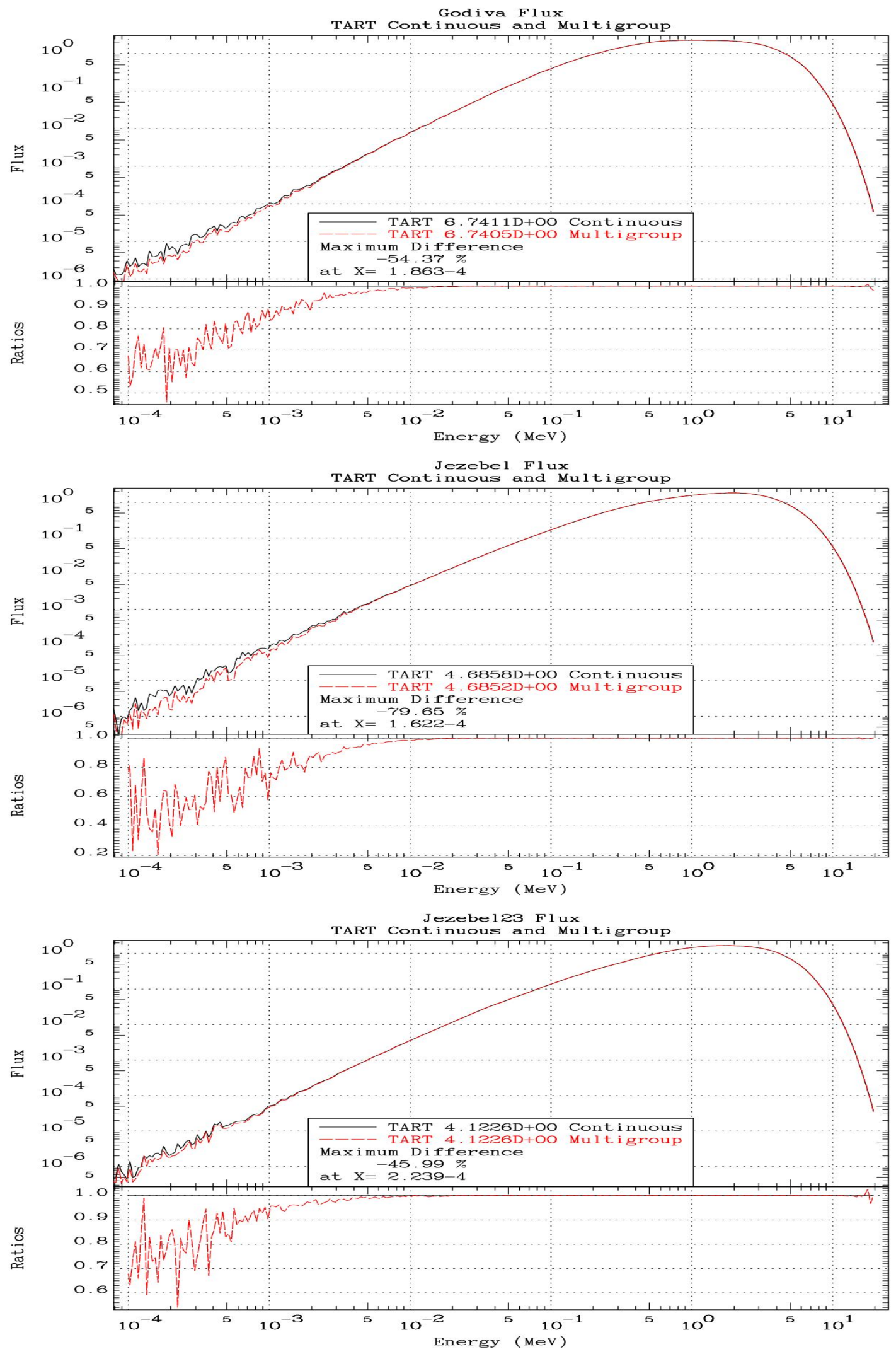


\section{Unresolved Resonance Region Self-Shielding}

One might think that by using continuous energy cross sections, rather than multi-group cross sections, the problem of self-shielding can be completely avoided. Unfortunately this is not the case, because one must still deal with self-shielding in the unresolved resonance energy range. In the unresolved resonance region we do not know the cross section as a continuous function of energy; we only know the probability distribution of the cross sections, and these distributions can result in important self-shielding effects; for a more detailed discussion of this subject, see ref [19].

Below we show the effect on the flux with and without an unresolved resonance region treatment; for these results we have used TART with (default) and without (input option) unresolved region self-shielding, to obtain comparable results for all three systems. Here we can see that without self-shielding in the unresolved resonance region the cross sections are too large, resulting in depression of the flux. For Godiva and Jezebel this effect can be seen above about $2 \mathrm{keV}$; for Jezebel23 it can be seen above about $500 \mathrm{eV}$. Below the lower energy limit of the unresolved region energy range is the resolved energy range; here self-shielding is accounted for. As a result in the resolved resonance region we can see that the flux tends to recover. This is quite different from the results shown above, where no self-shielding in included, leading to the flux continuing to decrease with decreasing energy.

\begin{tabular}{|c|c|c|c|c|c|c|}
\hline & $\begin{array}{c}\text { Godiva } \\
\text { Unresolved }\end{array}$ & $\begin{array}{c}\text { Godiva } \\
\text { No } \\
\text { Unresolved }\end{array}$ & $\begin{array}{c}\text { Jezebel } \\
\text { Unresolved }\end{array}$ & $\begin{array}{c}\text { Jezebel } \\
\text { No } \\
\text { Unresolved }\end{array}$ & $\begin{array}{c}\text { Jezebel23 } \\
\text { Unresolved }\end{array}$ & $\begin{array}{c}\text { Jezebel23 } \\
\text { No } \\
\text { Unresolved }\end{array}$ \\
\hline Flux & 6.74106 & 6.74080 & 4.68581 & 4.68551 & 4.12264 & 4.12258 \\
\hline Production & 1.00000 & 1.00000 & 1.00000 & 1.00000 & 1.00000 & 1.00000 \\
\hline Absorption & 0.43009 & 0.43009 & 0.32789 & 0.32790 & 0.38792 & 0.38792 \\
\hline Leakage & 0.56981 & 0.56977 & 0.67178 & 0.67173 & 0.61228 & 0.61228 \\
\hline Removal & 0.99990 & 0.99985 & 0.99967 & 0.99963 & 1.00020 & 1.00020 \\
\hline K-eff & 1.00010 & 1.00014 & 1.00033 & 1.00037 & 0.99980 & 0.99980 \\
\hline $\begin{array}{c}\text { Removal } \\
\text { Time } \\
\text { nanoseconds }\end{array}$ & 6.21739 & 6.21653 & 3.72884 & 3.72766 & 3.20305 & 3.20277 \\
\hline
\end{tabular}

As far as the energy dependent results for our seven codes, we can see differences because of self-shielding: 1) MERCURY uses continuous energy cross sections, but as yet does not have an unresolved resonance region treatment, 2) TRANSX can optionally account for self-shielding effects, and we can see this in the PARTISN results, but from the ARDRA and AMTRAN results we can see that these do not include TRANSX selfshielding.

Although in this case self-shielding in the unresolved resonance region has little effect on the integral parameters, this is not true in general. In systems with slower neutron spectra unresolved resonance self-shielding plays an important role. 

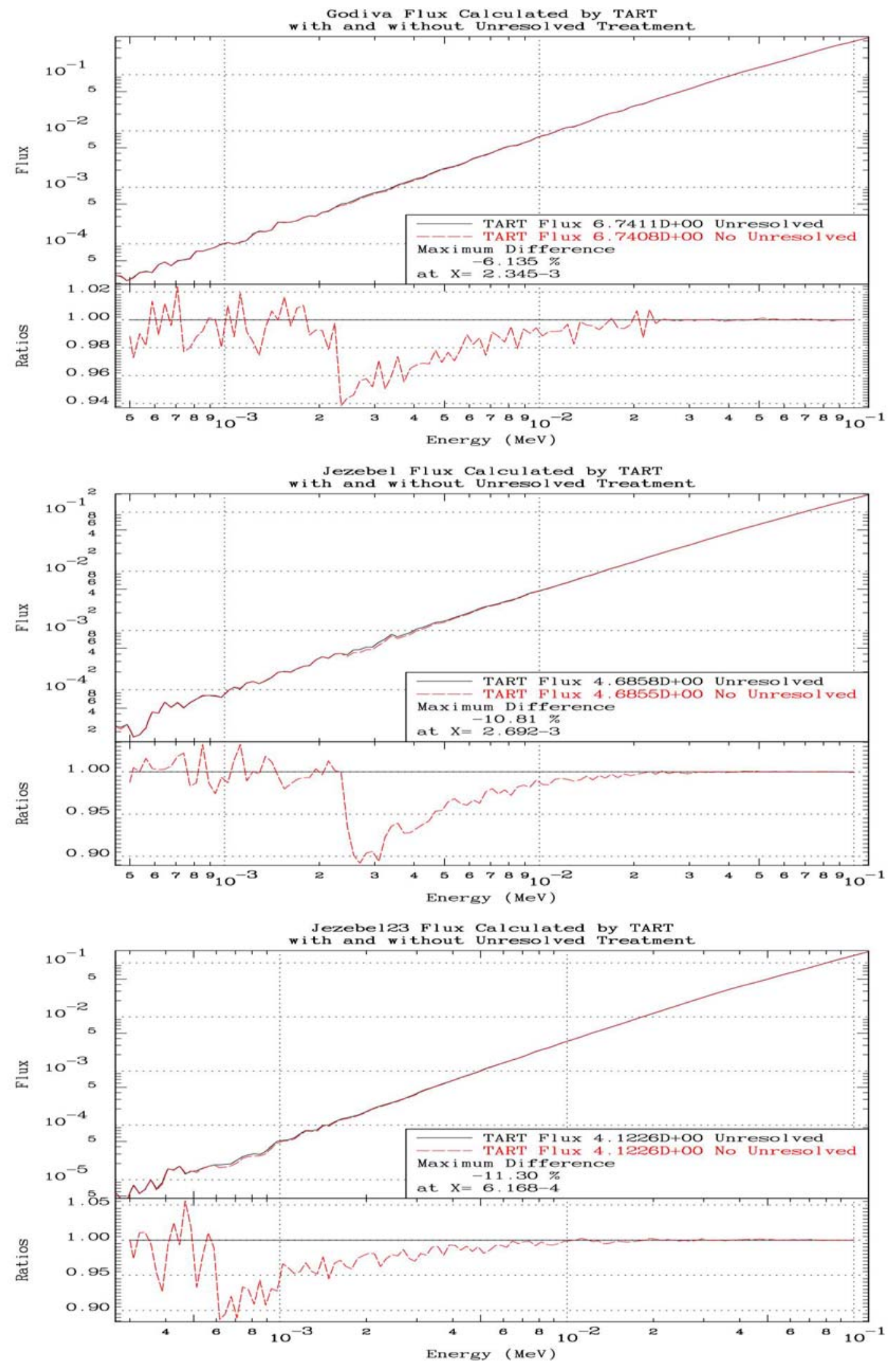


\section{Recommendations for Improving ENDF/B-VII.0}

Based on comparisons for this study and our earlier study [1] we found some differences between MCNP and TART results. Most of these can be traced to how these codes interpret ENDF/B data. A major difference is that the standard NJOY/MCNP treatment is to provide the "best" literal interpretation of all ENDF/B data; this is very important for data testing. In contrast TART treatment is to provide the "best" physical interpretation of data for use in TART's applications; obviously very important for applications. These differences in interpretation are reflected in the below recommendations.

Our tests demonstrate that at least for these three systems the newer ENDF/B-VII.0 data is a definite improvement over the older ENDF/B-VI.8 data. However, our tests indicate that VII.0 is not yet perfect, and here we mention a few points where we feel it could be even further improved, these include,

1) Improved delayed neutron spectra, i.e., no histograms

2) More precision in tabulated fission spectra.

3) Improvement reaction spectra, i.e., no histograms and $\sqrt{E}$ low $E$ variation

When ENDF/B-VII.0 was released in December 2006 the Cross Section Evaluation Working Group (CSEWG) declared that the library would be frozen for three years. If true, there is nothing we can do to improve the basic evaluated data until December 2009, but in the meantime we can take some actions to improve the interpretation of the data by our processing and transport codes. 


\section{Differences in delayed neutron spectra}

ENDF/.B delayed neutron spectra are defined by nuclear model code output, where the spectra are given by a series of histograms, each step of the histogram being about 10 $\mathrm{keV}$ wide. This $10 \mathrm{keV}$ width seems reasonable at high energy in the MeV, but is totally unrealistic at low energy to define the delayed neutron emission as a constant step between 0 and $10 \mathrm{keV}$, as shown in the figures below. MCNP interprets this exactly as given, whereas TART replaces the low energy shape by a more physically acceptable Maxwellian; see ref. [14] for details.

These histograms that come directly out of nuclear model codes should be improved to define more physically acceptable energy variation before they are used in ENDF/B evaluations. Since ENDF/B-VII.0 is frozen until December 2009 this obviously cannot be done today. However, until this is done TART [6] and NJOY [5] with its "smoothing" option (see the below example), attempt to improve this data for use today.

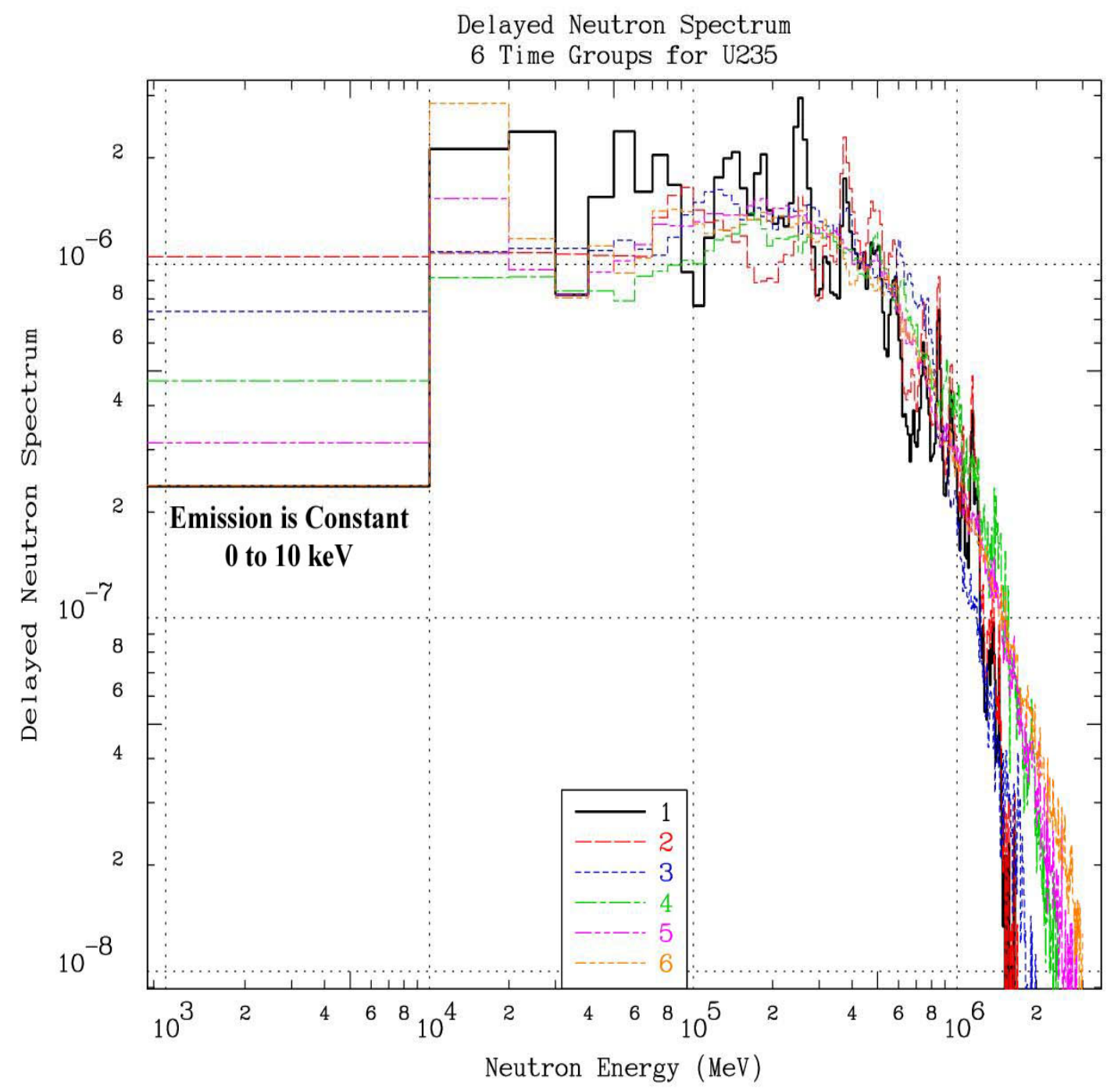




\section{Accuracy of ENDF/B-VII.0 Tabulated Fission Spectra}

At high energy the ENDF/B-VII.0 are not tabulated to a fine enough energy grid. We illustrate this point below where we first show the U235 fission spectrum tabulated at $1 \mathrm{MeV}$ incident neutron energy. Over most of the energy range the tabulated secondary energy points (small circles on plots) are closely enough spaced to accurately define the fission spectrum. But above $10 \mathrm{MeV}$ the spectrum is changing so rapidly that more energy points are needed to accurately define it. The first figure shows the tabulated VII.0 spectrum which between 10 and $30 \mathrm{MeV}$ changes by 7 orders of magnitude, and there are far too few points to accurately define this variation. The second plot shows the 10 to 20 $\mathrm{MeV}$ energy range where compared to an accurately tabulated spectrum, the VII.0 overestimates the value by up to over $8 \%$. Finally the third figure shows the 10 to 11 $\mathrm{MeV}$ energy range where the VII.0 evaluation only includes tabulated energy points at 10 and $11 \mathrm{MeV}$; obviously too few points to accurately define the shape. The fission spectra are so important that we recommend they always be tabulated to high accuracy over the entire secondary energy range.
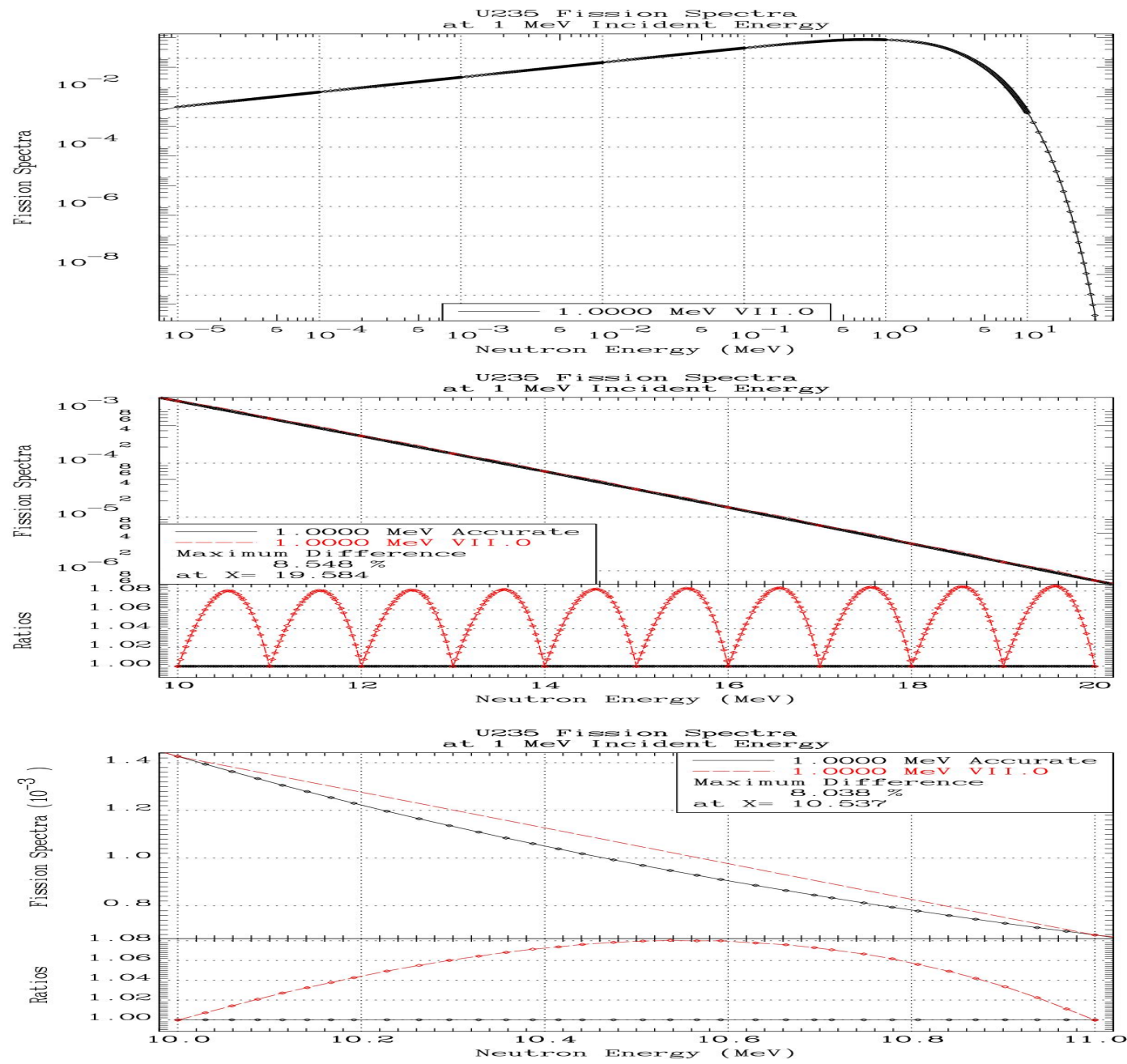


\section{Effect of low energy spectra smoothing}

Many ENDF/B spectra now use histograms. As stated earlier MCNP and TART results differ at very low energies because the two codes are interpreting the VII.0 data differently: MCNP results are based on its BEST literal interpretation of the VII.0 low energy histogram data, whereas TART results are based on smoothing the VII.0 results assuming what it considers to be a more physically acceptable $\sqrt{E}$ low energy variation (rather than histogram). NJOY [5] now includes a "smoothing" option to approximate the low energy $\sqrt{E}$ variation in a manner similar to TART.

The below plot illustrates the effect of NJOY "smoothing" on the U235 inelastic continuum (MT=91) spectrum for $1 \mathrm{MeV}$ incident neutrons. Physically the low energy spectra should have $\sqrt{E}$ variation, but what is output by nuclear model codes and used in ENDF/B-VII.0 is a series of histograms steps each roughly $10 \mathrm{keV}$ wide; this is adequate at higher energies, but it is a very poor approximation at very low energy. The NJOY "smoothing" option improves histogram spectra by replacing the original ENDF/B large histogram intervals by smaller energy steps to better approximate the $\sqrt{E}$ variation. Below we can see that NJOY "smoothing" results in a much more physically acceptable shape at low energy.

Hopefully in the future this histogram output from nuclear model codes can be improved to more realistically define a continuous energy variation of spectra, which will improve the ENDF/B data.

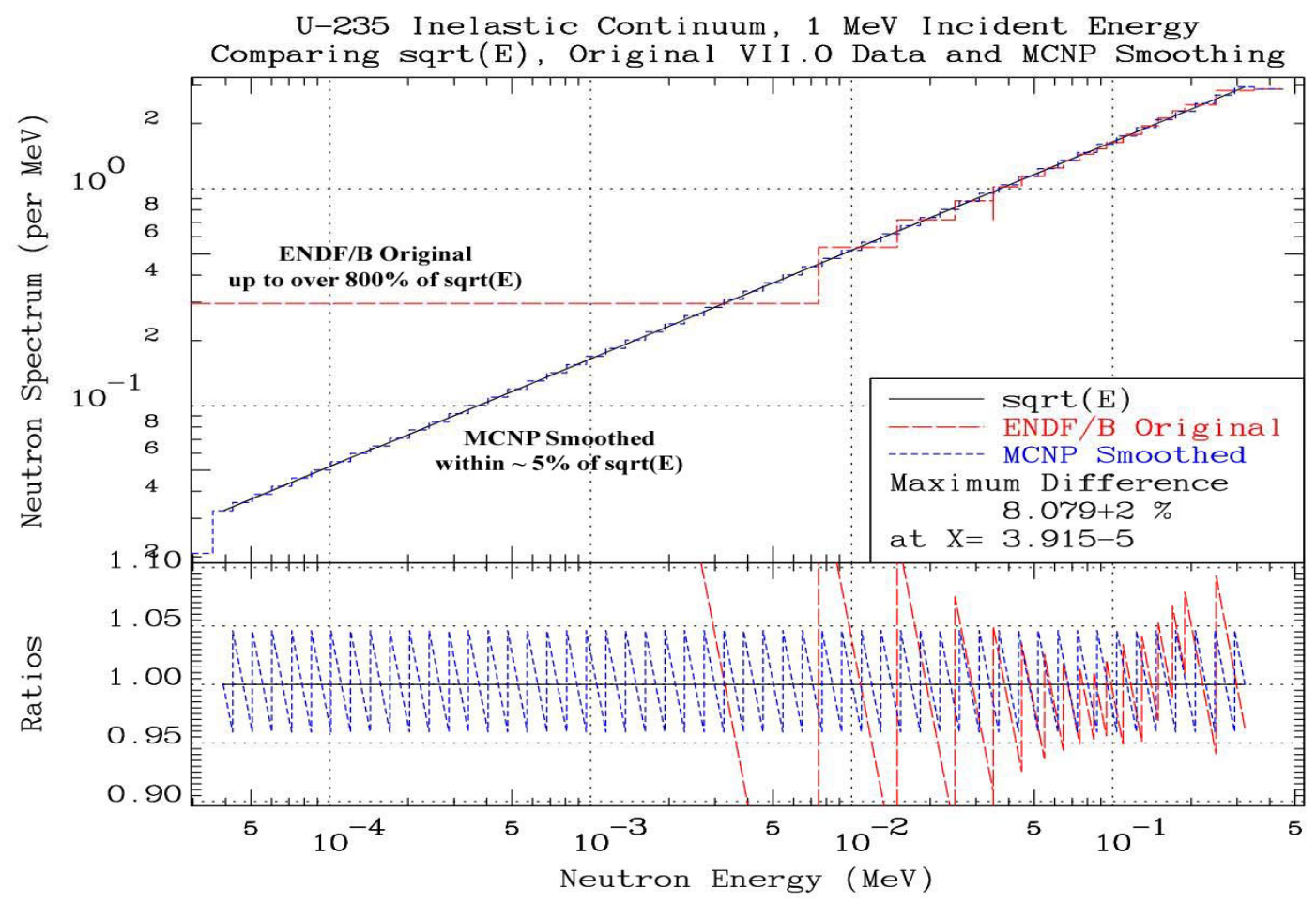




\section{NJOY's “smoothing” Option}

To illustrate the source of the differences at low and high energy, we can use NJOY's "smoothing" option, and the TART data used by TART and MERCURY. The figure below presents original MCNP results, as well as both MCNP and TART results, both using the same low energy $\sqrt{E}$ and high energy improved fission spectra "smoothing". From this figure it seems clear that this "smoothing" is the source of the differences. Comparing the MCNP Original and Smooth results, we can see from the below plot that in this case there is very little effect on the integral of the flux: 6.7419 vs. 6.7423 , differing only by 0.0004 . Comparing the MCNP Original and Smooth results for K-eff we find: 0.99986 vs. 0.99977 , differing only by 0.00009 , well below the $+/-0.001$ we consider acceptable. In principle both TART and MCNP "smooth" are using the same low and high energy approximations, but we can see from the below results that although the agreement is good it is not exact, showing that the actual details differ as to what each code is doing.

To repeat what was said earlier: for the three fast critical systems we are examining, these lower and higher energy ranges are not important when defining K-eff., but this may not be generally true. Here we explain the sources of the differences to insure that we understand them, which in turn can lead to better general agreement between our codes and wider applicability of our codes to other problems.

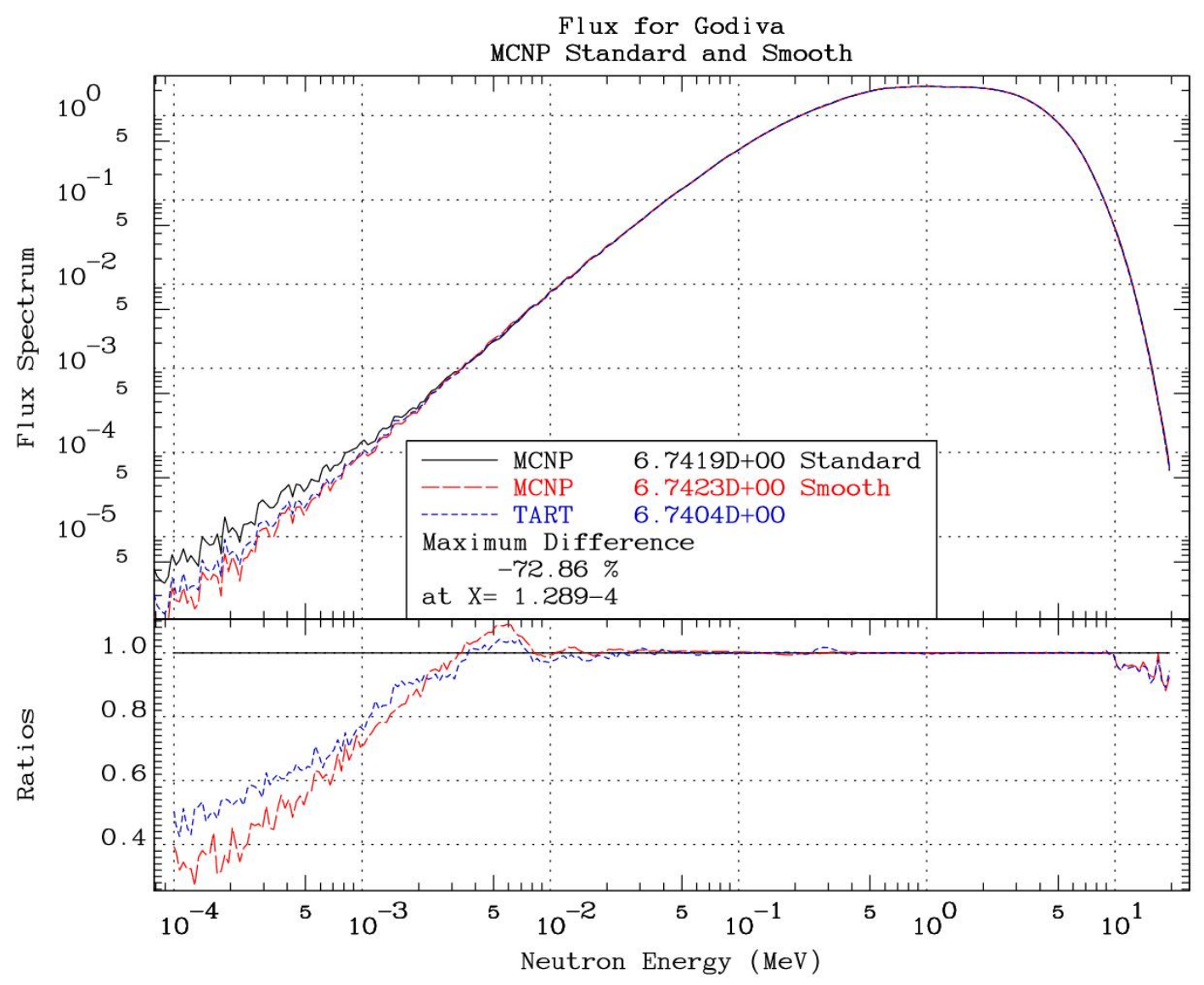


Flux for Godiva

MCNP Standard and Smooth

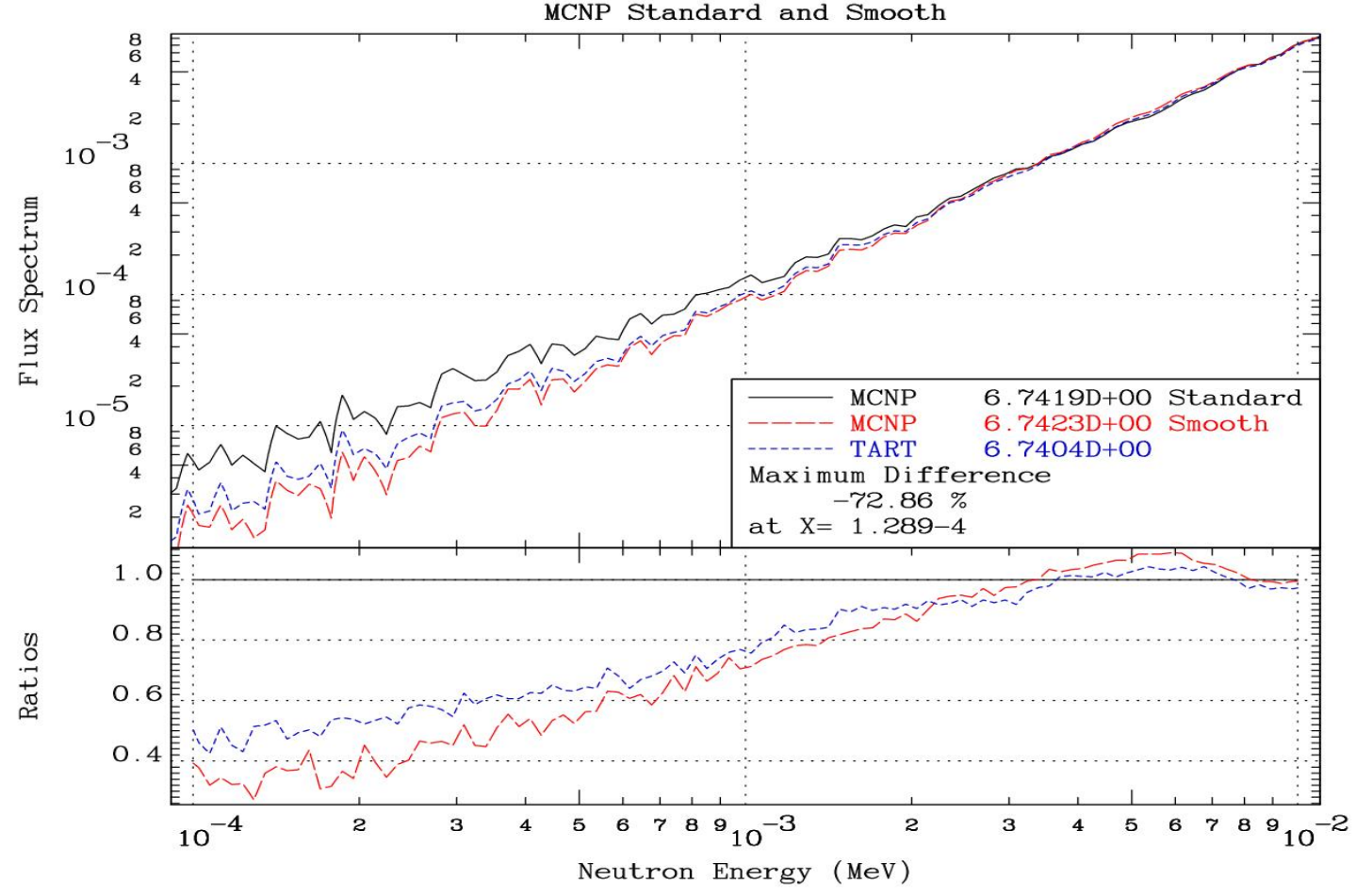

Flux for Godiva

MCNP Standard and Smooth

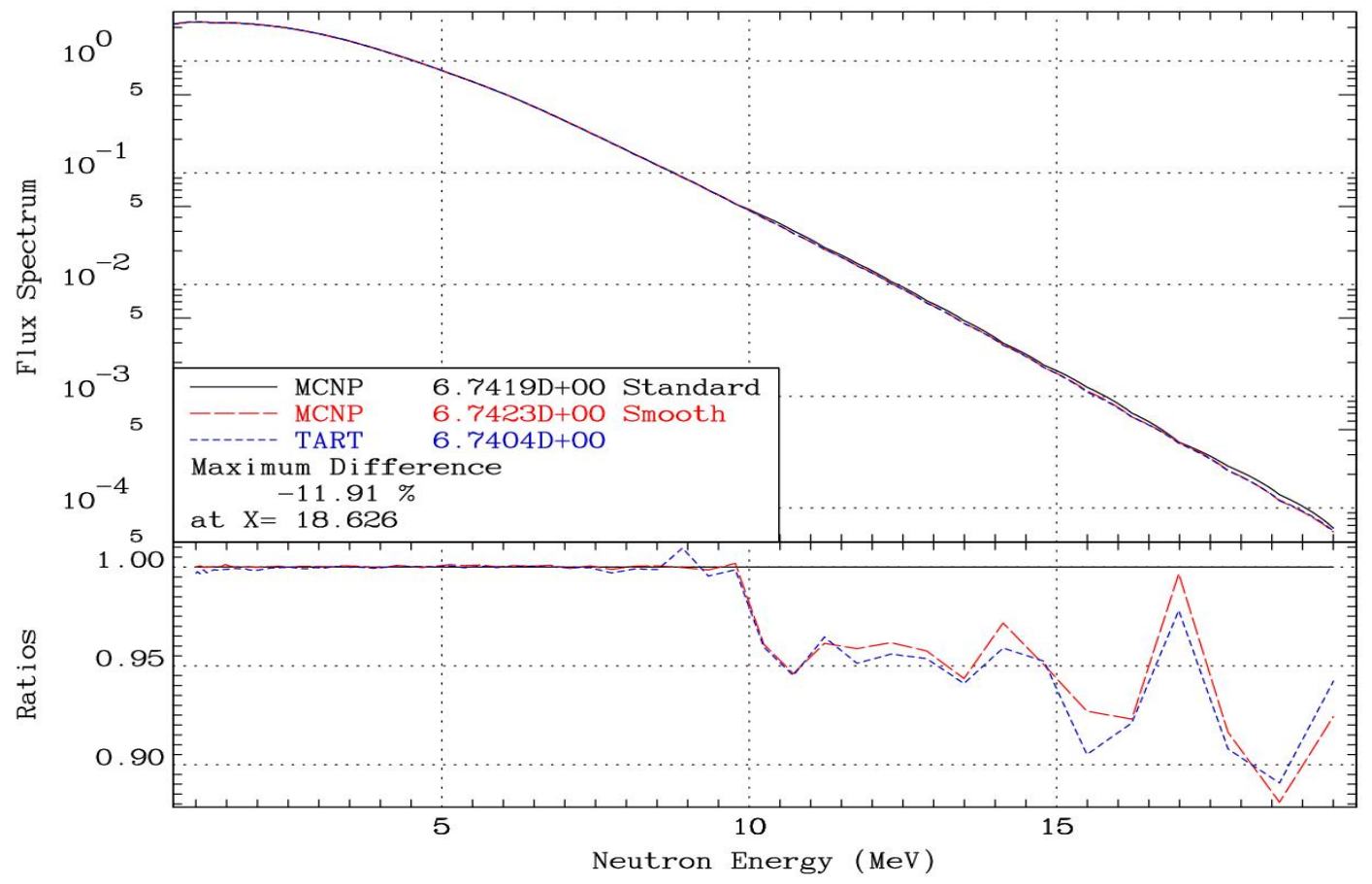




\section{The Godiva "Bump"}

Usually one of the big advantages of code comparisons is that when we see a difference between two codes by comparing results from many codes we can easily explain the source of the difference, see that one code does not agree with all of the other codes, and correct the code. This approach has led to many improvements in our codes - and often also in our data.

During this study we identified the sources of differences we saw at low and high energies, presented methods for how we can handle these differences today and we made recommendations as to how the evaluated data can be improved to generally address these problems in the future.

The one difference we have at yet not been able to explain is what we call the $300 \mathrm{keV}$ "bump" in the Godiva results. We can now compare results from a variety of different Monte Carlo codes. Using MCNP as a standard to ratio everything to, four codes show a "bump" (CE-KENO, MERCURY, TART, VIM) and four codes do not (MCNP, MONK, COG, TRIPOLI). Keeping an open mind as to which codes are correct, either four independent codes produce a minimum near $400 \mathrm{keV}$ following by a maximum near 300 $\mathrm{keV}$, or else MCNP produces a maximum near $400 \mathrm{keV}$ followed by a minimum near 300 $\mathrm{keV}$. We have tested many features of the codes but we still cannot explain this behavior. So our parting word will just have to be: obviously still more works needs to be done.

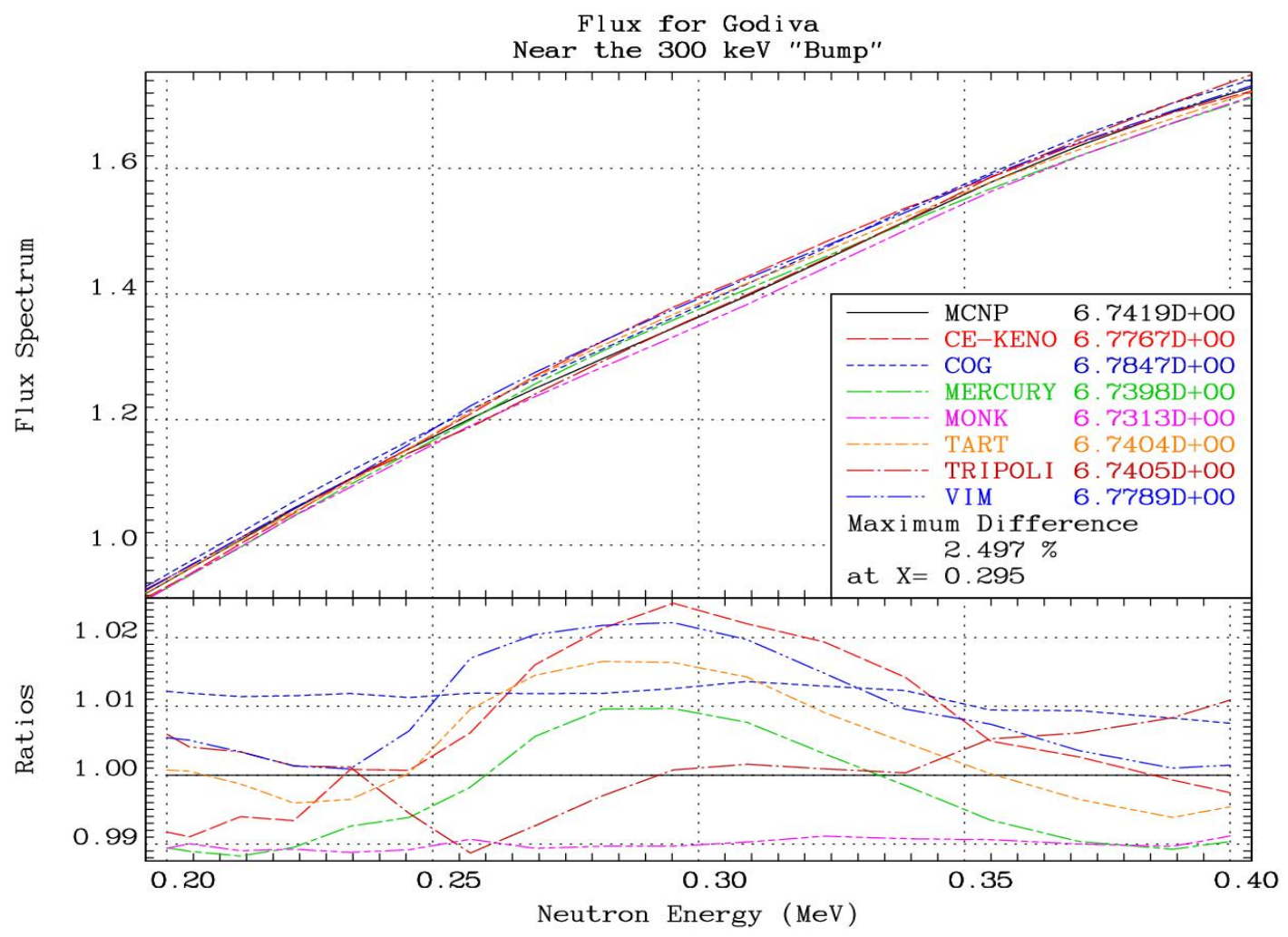




\section{Conclusions}

In an earlier report [1] we considered three fast critical assemblies, each assembly is dominated by a different nuclear fuel: Godiva (U235), Jezebel (Pu239) and Jezebel23 (U233) [2]. We first showed the improvement in results when using the new ENDF/BVII.0 data [3], rather than the older, now frozen, ENDF/B-VI.8 data [4]. Next, we showed that our results could be obtained using any of a variety of Monte Carlo codes, i.e., the results were not specific to any single transport code.

In this paper our emphasis is only on our codes, rather than the nuclear data they use. For this paper all of our codes used the ENDF/B-VII.0 data [3], that we had already tested [1]. In this paper we concentrate on the same three critical assemblies, but here the emphasis is on demonstrating that we obtain the same results using any of the LANL and LLNL Monte Carlo and Sn codes. Here we show recent improvements in our Monte Carlo codes, and major improvements in our Sn results; at the time of our earlier paper [1] we had not yet achieved agreement between our Monte Carlo and Sn results, so that only our Monte Carlo results were published in our earlier report, allowing us time to investigate the source of the differences between our Monte Carlo and Sn results. All of these differences have now been eliminated.

The bottom line is that in this report we show that using any of the LANL and LLNL Monte Carlo or Sn codes we obtain consistent integral and differential results. Furthermore it is worth noting that when any of these codes use the new ENDF/B-VII.0 data library, for the first time we are able to reproduce the expected K-eff values for all three assemblies to within the quoted accuracy of the models, namely $1.0+/-0.001$. This is a BIG improvement compared to the results obtained using the older ENDF/B-VI.8 data library. 


\section{References}

[1] “ENDF/B-VI.0 Data Testing for Three Fast Critical Assemblies”, Dermott E. Cullen, et al Lawrence Livermore National Laboratory, UCRL-TR-233310, June 2007

[2] International Handbook of Evaluated Criticality Safety Benchmark Experiments, NEA/NSC/DOC(95)03, September 2006 edition, editor Blair Briggs

[3] POINT 2007: A Temperature Dependent ENDF/B-VII.0 data Cross Section Library, by Dermott E. Cullen, UCRL-TR-228089, February 2007, currently on-line at http://www-nds.iaea.org/point2007/

[4] POINT 2004: A Temperature Dependent ENDF/B-VI, Release 8 Cross Section Library, by Dermott E. Cullen, Lawrence Livermore National Laboratory, UCRL-TR202284, April 2004, currently on-line at http://www-nds.iaea.org/point2004/

[5] NJOY: "The NJOY Nuclear Data Processing System, Version 91," Los Alamos National Laboratory report LA-12740-M, by R. E. MacFarlane and D. W. Muir, (October 1994) is still the latest official manual.

[6] TART 2005: A Coupled Neutron-Photon 3-D, Time Dependent, Combinatorial Geometry Monte Carlo Transport Code, by Dermott E. Cullen, Lawrence Livermore National Laboratory, UCRL-SM-218009, November 22, 2005.

[7] AMTRAN: Parallel deterministic neutron transport with AMR, by C.J. Clouse, in F. Graziani (Ed.), Computational Methods in Transport, Springer-Verlag, 2006, pp. 499--512.

[8] ARDRA, scalable parallel code system to perform neutron and radiation transport calculations, by U. Hanebutte and P.N. Brown, Tech. Report UCRL-TB-132078, Lawrence Livermore National Laboratory, 1999.

[9] COG - A Multiparticle Monte Carlo Transport Code, User’s Manual, Fifth Edition, Richard M. Buck, Edward Lent, Tom Wilcox, Stella Hadjimarkos, UCRL-TM-202590, September 1, 2002.

[10] MCNP - A General Monte Carlo N-Particle Transport Code, Version 5, Volume I: Overview and Theory, X-5 Monte Carlo Team, Los Alamos National Laboratory report LA-UR-03-1987 (April 24, 2003). Portions of the MCNP manual are available on-line at http://www-xdiv.lanl.gov/x5/MCNP/themanual.html

[11] MERCURY: User Guide (Version b.8), Lawrence Livermore National Laboratory, Report UCRL-TM-204296, Revision 1, by R. J. Procassini and J. M. Taylor, (2005), more information concerning MERCURY is available online at http://www.llnl.gov/mercury 
[12] "PARTISN: A Time-Dependent, Parallel Neutral Particle Transport Code System,", by Ray E. Alcouffe, Randal S. Baker, Jon A. Dahl, Scott A. Turner, and Robert C. Ward, Los Alamos National Laboratory report LAUR-05-3925 (rev. May 2005).

[13] “Physics of Nuclear Kinetics”, by G. Robert Keepin, Addison Wesley (1965)

[14] “A Simple Model of Delayed Neutron Emission”, by Dermott E. Cullen, Lawrence Livermore National Laboratory, UCRL-TR-204743, June 2004, currently on-line at http://www.llnl.gov/cullen1/Papers/delayed/Delayed.pdf

[15] NDFGEN: "LLNL's deterministic transport access routines and data”, by B.R.Beck, Lawrence Livermore National Laboratory, UCRL-MA-1479647, 2002.

[16] MCFGEN: The Content and Structure of MCF Files”, by G.W.Hedstrom, L,J. Cox, and S.T.Perkins, Lawrence Livermore National Laboratory, UCRL-ID-127438, Rev. 1, 1997.

[17] "TRANSX2: A Code for Interfacing MATXS CrossSection Libraries to Nuclear Transport Codes,", by R. E. MacFarlane, Los Alamos National Laboratory report LA-122312-MS (July 1992).

[18] “PREPRO 2007: 2007 ENDF/B pre-processing Codes”, IAEA-NDS-39, Rev. 13, March 17, 2007, by Dermott E. Cullen, Nuclear Data Section, International Atomic Energy Agency, Vienna, Austria.

[19] "Nuclear Cross Section Processing", by Dermott E. Cullen, Chapter I: Handbook of Nuclear Reactor Calculation, vol. I, Yigal Ronen, Editor, CRC Press, inc., Boca Raton, Florida (1986). 


\section{Appendix A: Contact Information}

Dermott E. Cullen

Lawrence Livermore National Laboratory

P.O.Box 808/L-159

Livermore, CA 94550

Tele: 925-423-7359

E.Mail: cullen1@llnl.gov

Website:

http://www.comcast.net/ redcullen1

Peter N. Brown

Center for Applied Scientific Computing

Lawrence Livermore National Laboratory

P.O. Box 808, L-561

Livermore, CA 94551

Tele: 423-2098

E.Mail: pnbrown@llnl.gov

Website:

http://www.llnl.gov/CASC/people/brown/

Edward Lent

Lawrence Livermore National Laboratory

P.O.Box 808/L-198

Livermore, CA 94550

U.S.A.

E.Mail: lent1@llnl.gov

\section{Robert MacFarlane}

MS B243 T-16

Los Alamos National Laboratory

Los Alamos, NM 87545 USA

Tele: 505-667-7742

E.Mail: ryxm@lanl.gov

Scott McKinley

Defense and Nuclear Technologies

Lawrence Livermore National Laboratory

L-95 LLNL

7000 East Ave.

Livermore, CA 94551

U.S.A.

Tele: 925-424-2738

E.Mail: mckinley9@llnl.gov

Website: http://www.llnl.gov/Mercury 
University of California

Lawrence Livermore National Laboratory

Technical Information Department

Livermore, CA 94551

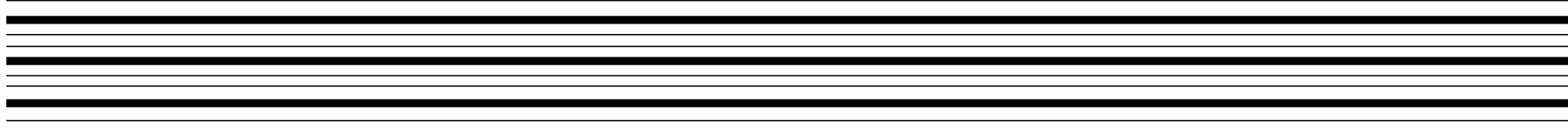

